\title{
Enhancing cancer targeting of Y9ס2TCR through modified NKG2D co-stimulation
}

Patricia Hernández-López ${ }^{1}$, Eline van Diest ${ }^{1}$, Inez Johanna ${ }^{1}$, Sabine Heijhuurs ${ }^{1}$, Trudy Straetemans ${ }^{1}$, Zsolt Sebestyén ${ }^{1}$, Dennis X. Beringer ${ }^{1}$, and Jürgen Kuball ${ }^{1,2}$

${ }^{1}$ Center of Translational Immunology, University Medical Center Utrecht, Utrecht University, Utrecht, Netherlands, ${ }^{2}$ Department of Hematology, University Medical Center Utrecht, Utrecht, Netherlands

Funding sources: This project was supported by KWF UU 2014-6790 \& 11393 and Gadeta.

COI: JK is shareholder of Gadeta. JK, ZS, EvD, and DB are inventors on patents with YठTCR related topics.

Correspondence should be addressed to J.K.(J.H.E.Kuball@umcutrecht.nl)

Corresponding author's address: Laboratory of Translational Immunology, University Medical Center Utrecht, Utrecht University, 3584 CX Utrecht, The Netherlands

Corresponding author's phone: +31 (0)88 7557230 
bioRxiv preprint doi: https://doi.org/10.1101/2021.01.06.424553; this version posted January 7, 2021. The copyright holder for this preprint (which was not certified by peer review) is the author/funder. All rights reserved. No reuse allowed without permission.

Modified NKG2D as co-stimulation Hernández-López et al. 


\section{Abstract}

Despite the ability of $\gamma \delta \mathrm{T}$ cells to mediate tumor killing independently of $\mathrm{MHC}$ recognition, all the clinical trials that have been carried out using these cells showed low response rate in patients, in part due to its poor proliferation ability. Recently, a new generation of CAR-T cells called $\alpha \beta T$ cells engineered to express a defined $y \delta T C R$ (TEG) has been developed. TEGs are $\alpha \beta T$ cells engineered to express a defined $\gamma \delta T C R$. These cells are able to mediate effective antitumor reactivity without showing any reactivity towards healthy tissue, and combine the best qualities of both $\alpha \beta T$ and $\gamma \delta T$ cells. In fact, the high affinity $Y 9 \delta 2 T C R$ clone 5 has recently been selected within the TEG format as a clinical candidate (TEG001). Here we present a strategy to improve the antitumor activity of TEG001 by co-expressing an activating chimeric co-receptor together with y $\delta T C R-$ Cl5.Therefore, we developed three different co-receptors by fusing the extracellular domain of the activating cell surface receptor NKG2D, that is able to bind stress induced ligands typically expressed on tumor cells, to the cytoplasmic signaling domains of the $T$ cell costimulatory proteins ICOS, CD28 and 4-1BB. We determined that introduction of the chimeric co-receptors NKG2D-CD28 ${ }_{w t}$ and NKG2D-4-1BB ${ }_{C D 28 T M}$ improved the activity of TEG001 against tumors that were recognized by yסTCR-Cl5 and expressed NKG2D ligands, but did not affect tumors that either were not recognized by үठTCR-Cl5 or did not express NKG2D ligands. This 'chimeric co-receptors' approach open a wide range of opportunities that lead to a next generation of TEGs. 


\section{Introduction}

It has been demonstrated that TEGs ( $\alpha \beta T$ cells engineered to express a defined $\gamma \delta T C R$ ) mediate effective antitumor reactivity without showing any reactivity towards healthy tissue and present a novel class of CAR T which has the potential to target many different tumor types [1]. For CAR T, despite its huge success in the clinic further improvements have been suggested such as dual receptor signaling in order to increase safety and or efficacy [2]. In this light we explored whether either changing signaling domains of the Y $\delta T C R$ or providing additional costimulatory signals could improve performance of TEGs. Different signaling capacities of $\alpha \beta T C R$ and $y \delta T C R$ have been reported to impact long term memory formation of $\gamma \delta T$ cells [3] CD8 ${ }^{+}$TEG activity has been reported to be partially supported through endogenous NKG2D [4]. NKG2D is an activating cell surface receptor that is able to bind to 8 different several stress induced ligands (MICA/B and ULBP1-6) that are overexpressed in many tumor cells but absent or present at low levels in healthy cells [5]. NKG2D-NKG2D ligand interaction has been shown alone to be sufficient to induce killing of tumor cells through $y \delta T$ cells [6] and NK cells [5]. As consequence NKG2D CAR $\alpha \beta T$ cells have been explored in clinical trials but showed no substantial efficacy in patients suffering from acute myeloid leukemia [7]. Reasons of failure might be that NKG2D alone without additional coreceptor support does not exploit its full activity or that the used design which partially depended on DAP10 signaling rapidly exhausts and contributed to education of engineered immune cells. үठT cells and NK cells have been shown to quickly adopt to new environments and get educated over time, thus tolerant $[8,9]$. Within this context we explored whether adding NKG2D to CD4+ and CD8+ $T$ cells in its wild-type version or with altered signaling domains can further enhance the promising and broad anti-tumor activity of a $y 9 \delta 2 T C R$. As additional signaling domains different costimulatory proteins (ICOS, CD28 and 4-1BB) that are typically expressed on T cells and also used for CAR T engineering [2] have been explored. 


\section{Material and Methods}

\section{Antibodies}

The following antibodies were used: anti-CD8a-PerCP-Cy5.5 (1:100; clone RPA-T8; 301032), CD4-AF700 (1:40; clone RPA-T4; 300526), aßTCR-PE-Cy5 (1:80; clone IP26; 11-9986-42) from Biolegend; $ү \delta T C R-P E-C y 7 ~(1: 20 ;$ clone IMMU510; B10247) from Beckman Coulter;NKG2D-PE (1:20; clone 1D11; 320806), NKG2D-BV650 (1:40; clone 1D11; 563408) and үסTCR-APC (1:5; clone B1; 555718) from BD Biosciences.

\section{Cell lines and cell culture}

Daudi, K562, HL60, Jurkat, RPMI-8226 and Phoenix-Ampho cells were obtained from ATCC. Phoenix-Ampho cells were cultured in DMEM supplemented with $1 \%$ Pen/Strep (Invitrogen) and 10\% FCS (Bodinco, Alkmaar, The Netherlands). All other cell lines were cultured in RPMI with 1\% Pen/Strep and 10\% FCS. Primary fresh PBMCs were isolated by Ficoll-Paque (GE Healthcare, Eindhoven, The Netherlands) from buffy coats supplied by Sanquin Blood Bank (Amsterdam, The Netherlands).

\section{Construction of chimeric NKG2D receptors}

Six chimeric receptors were constructed (for sequences see Appendix I). cDNAs for coreceptors were synthetized by BaseClear (Leiden, Netherlands). Type II co-receptors were created using overlap extension PCR. For the first reaction DNA coding for cytoplasmic signaling domains of ICOS and CD28, both extended with 18 nucleotides of the NKG2D transmembrane sequence were amplified using the following primers; for ICOS "ICOScyto_FW1" and "NKG2D_OIEx_RV1", and for CD28 "CD28cyto_FW1" and "NKG2D_OIEx_RV1". For the second reaction the DNA for "4-1BBcyto-NKG2D tm + ec" was used as template for the transmembrane and extracellular domain of NKG2D and was amplified using the following primers "NKG2D_FW2" and "NKG2D_BamHI_RV2". In reaction 3 the products of reaction 1 were fused to the product of reaction 2 using "ICOScyto_FW1" and "NKG2D_BamHI_RV2" for ICOScyto-NKG2D, and "CD28cyto_FW1 " and "NKG2D_BamHI_RV2" for CD28cyto-NKG2D. All type I and II constructs were subcloned into pBullet using $\mathrm{Ncol}$ and $\mathrm{BamHI}$ as restriction sites. 
In similar fashion as the type II constructs the transmembrane and linker domains of the

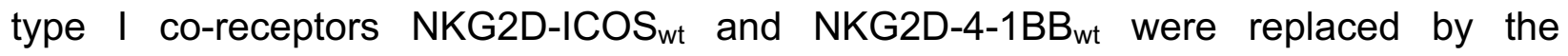
transmembrane and linker domains of NKG2D-CD28 ${ }_{w t}$ chimera using overlap extension PCR. In reaction 1 NKG2D-CD28linker-tm was amplified using primers "P2A_FW2 " and "CD28tm_RV2" and in reaction 2 the signaling domains of ICOS and 4-1BB were amplified using primers "ICOS_FW1" or "41BB_FW1" in combination with "pmp71_RV". In reaction 3 the PCR products of reaction 1 and 2 were fused using primers "P2A_FW2" and "pmp71_RV". They were subcloned into pMP71 already containing YठTCR-Cl5, using Xhol and HindIII. All restriction enzymes were supplied by NEB (Massachusetts, USA).

\section{Retroviral transduction of $\alpha \beta T$ cells and cell lines}

Briefly, packaging cells (Phoenix-Ampho) were transfected with helper constructs gagpol (pHIT60), env (pCOLT-GALV) and pMP71 or pBullet retroviral vectors containing genes codifying for the different proteins. In the case of human PBMCs, they were preactivated with anti-CD3 (30 ng/mL; Orthoclone OKT3; Janssen-Cilag) and IL-2 (50 IU/mL; Proleukin, Novartis). Both, PBMCs and cell lines, were transduced twice with viral supernatant within 48 or 3 hours respectively, in presence of $6 \mathrm{mg} / \mathrm{mL}$ polybrene (SigmaAldrich). For PMBCs $50 \mathrm{IU} / \mathrm{mL}$ of IL-2 was added. TCR-transduced T cells were expanded by stimulation with anti-CD3/CD28 Dynabeads $\left(500,000\right.$ beads $/ 10^{6}$ cells; Life Technologies) and IL-2 (50 IU/mL). Thereafter, TCR-transduced T cells were depleted of the non-engineered T cells.

\section{Depletion of non-engineered T cells}

$\alpha \beta T$ cells transduced with $y \delta T C R-C l 5$ either alone or together with NKG2D wild type or the different NKG2D chimeras were incubated with a biotin-labeled anti- $\alpha \beta T C R$ antibody (clone BW242/412; Miltenyi Biotec, Bergisch Gladbach, Germany) and subsequently incubated with an anti-biotin antibody coupled to magnetic beads (anti-biotin MicroBeads; Miltenyi Biotec). Thereafter, the cell suspension was loaded onto an LD column and $\alpha \beta T C R+T$ cells were depleted by MACS cell separation per the manufacturer's protocol (Miltenyi Biotec). After depletion, TEGs were expanded using T cell REP. 


\section{Selection of engineered T cells}

After $\alpha \beta$-depletion, T cells were selected using human CD4 microbeads and MS columns (Miltenyi Biotec). Procedure was carried out according to manufacturer's protocol. For Jurkats, CD3 selection was performed after being transduced with yరTCR-Cl5 using human CD3 microbeads (Miltenyi Biotec). Moreover, another selection was carried out in these cells after the transduction of the different NKG2D-chimeras. First, cells were incubated at room temperature for $30 \mathrm{~min}$ using a 1:20 dilution of anti-NKG2D-PE in MACs buffer (PBS, 2\% FCS, 2mM EDTA). Cells were washed once with MACs buffer. After washing, cells expressing NKG2D were selected using anti-PE microbeads (Miltenyi Biotec) following manufacturer's protocol.

\section{NKG2D ligand staining}

The expression of NKG2D ligands in tumor cell lines was assessed using Recombinant Human NKG2D Fc Chimera Protein (R\&D systems, Abingdon, UK). $10^{5}$ tumor cells were incubated either with $0.5 \mu \mathrm{g}$ of NKG2D Fc recombinant protein or IgG1-Fc during $30 \mathrm{~min}$. Cells were washed with FACs buffer (1\% BSA, 1\% Na+azide) and secondary antibody IgG-PE (Southern Biotech, Alabama, USA) was added in a 1:200 dilution. Cells were fixed using 1\% PFA in PBS. Samples were measured on a BD LSRFortessa and FACSDiva (BD) software was used for data analysis.

\section{Functional T cell assays.}

To assess $T$ cell activation by surface recaptor expression like CD69 a FACS-based assay was used. To allow better differentiation on FACs, target cells were labeled using Cell Trace Violet Proliferation Kit (Thermo Fisher Scientific, Massachusetts, USA). T cells were resuspended at $1 \times 10^{6} \mathrm{cell} / \mathrm{ml}$ in $2 \mu \mathrm{M}$ Cell Trace Violet in PBS solution. Cells were washed two times with complete RPMI medium and resuspended in culture medium. After labelling, $10^{5}$ transduced Jurkats and $2 \times 10^{5}$ target cells were co-cultured for 18 hours in round-bottom 96-well plates in presence or absence of $100 \mu \mathrm{M}$ pamidronate. After incubation, cells were harvested and analyzed by flow cytometry to check CD69 expression. For cytokine detection $5 \times 10^{4}$ effector T cells and $5 \times 10^{4}$ target cells were co-cultured for 18 hours in round-bottom 96-well plates in presence or absence of 
pamidronate. After incubation, supernatants were collected and either frozen or used to detect IFNy levels straight away. ELISA was performed using IFN gamma Human Uncoated ELISA Kit (Thermo Fisher Scientific, Massachusetts, USA). For assessing cytotoxicity $5 \times 10^{3}$ RPMI 8226 cells expressing luciferase-GFP were co-cultured with the different effector $T$ cells at several effector: target ratios $(30: 1,10: 1,3: 1$ or 1:1) for 18 hours in round-bottom 96-well plates. Co-cultures were done in presence or absence of $10 \mu \mathrm{M}$ pamidronate. RPMI-8226 luciferase-GFP transduced tumor cells were used as targets. After incubation, luciferin was added at $12,5 \mathrm{ug} / \mathrm{ml}$ to each well and signal was measured on Softmax pro machine. Specific lysis was calculated using the formula \% specific lysis $=100 \times[$ (experimental data-spontaneous cell death $) /($ maximum cell death - spontaneous cell death)]. When this calculation provided a negative value, $0 \%$ was assigned as the result. In order to assess proliferation $T$ cells were resuspended at $1 \times 10^{6}$ cells $/ \mathrm{ml}$ using a $2 \mu \mathrm{M}$ solution of CellTrace ${ }^{\mathrm{TM}}$ Violet Cell Proliferation Kit (Thermo Fisher Scientific, Massachusetts, USA) in PBS. The cell suspension was incubated for 20 min at $37^{\circ} \mathrm{C}$. Cells were washed two times with complete RPMI medium and resuspended in culture medium. After labelling, 2,5 $\times 10^{5}$ effector $T$ cells were co-cultured together with $2,5 \times 10^{5}$ tumor cells in 48-well plates for 6 days. $100 \mu \mathrm{M}$ pamidronate was added to cultures boost recognition. On day 4 , medium was replaced. On day 6 , cells were analyzed by flow cytometry. 


\section{$\underline{\text { Results }}$}

\section{Design and expression of $\alpha \beta-\gamma \delta T C R$ chimera}

As signaling of $\alpha \beta T C R$ and $ү \delta T C R$ differ and this could impact as reported long term memory formation [3] we explored stability and function of different designs of $\alpha \beta-\gamma \delta$ TCR chimeras. A first version of three different $\alpha \beta-\gamma \delta$ TCR chimeras was generated (Supplementary figure $1 \mathrm{~A}$ ), but only one of them showed stable expression in Jurkat 76 (Supplementary Figure 1B). However, it was not able to induce activation of Jurkats-76 (Supplementary figure 1C). We hypothesized that this lack of activity could be due to the existing differences in the variable-constant interphases of $\gamma \delta$ and $\alpha \beta$ TCRs. Therefore, we generated three new designs modifying those interphases (Supplementary figure 2A). Moreover, interphase between both constant domains was modified to increase pairing and mouse residues were added to the $\beta$-constant chain to improve detection. In this case two of them were expressed (Supplementary figure 2B), but again all chimeric TCR variants were not able to induce activation of Jurkat-76 (Supplementary figure $2 \mathrm{C}$ ) and therefore this option was not further explored.

\section{Design and expression of NKG2D chimeras}

In order to assess whether adding NKG2D co-receptor signaling to CD4+ and CD8+ TEGs can further improve activity in addition to the wild-type version of NKG2D further constructs were engineered by fusing the extracellular domain of NKG2D to the cytoplasmic signaling domains of three different costimulatory proteins (ICOS, CD28 and 4-1BB). The natural orientation of NKG2D differs however from the other three costimulatory proteins. ICOS, CD28 and 4-1BB are type I transmembrane proteins $(\mathrm{N}$ terminal is outside of the cell), while NKG2D is a type II membrane protein ( $\mathrm{N}$-terminal domain is inside of the cell) that does not contain any known signaling motif within its intracellular domain. Therefore, NKG2D associates in natural $y \delta T$ cells or NK cells with the adaptor protein DAP10 via charged residues in its transmembrane domain [8]. Taking 
all this into account, two different types of chimeras were designed and generated. Firstly, in line with the natural design of NKG2D, a type II membrane protein was designed (Figure 1A, depicted as "type II design") by fusing the transmembrane domain of NKG2D to the cytoplasmic domains of ICOS, CD28 or 4-1BB. In addition, a type I design was created by fusing extracellular domains of NKG2D to the cytoplasmic domains of ICOS, CD28 or 4-1BB (Figure 1B). Consequently, linker and transmembrane domains were different for all constructs for the "type I design", while in the "type II design" only the signaling domain differed.
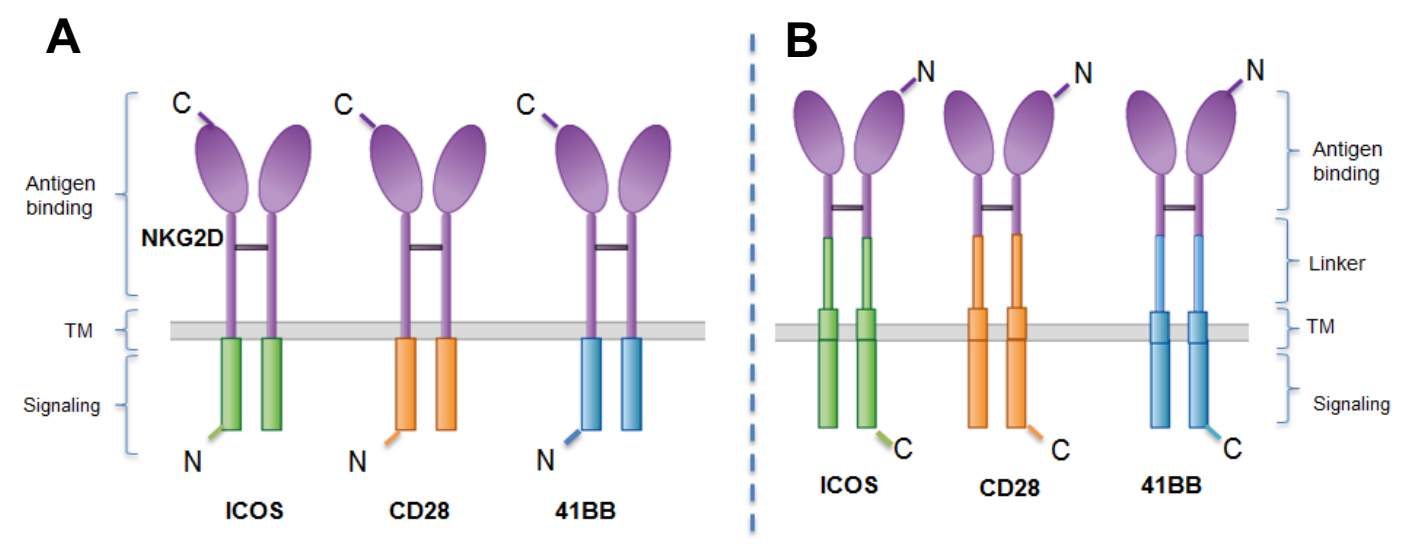

Figure 1. Schematic diagram of type lland type I chimeric NKG2D co-receptors. NKG2D, ICOS, CD28 and 4-1BB regions are colored in purple, green, orange and blue, respectively. (A) "Type II design". The natural NKG2D type II structure is preserved and signaling domains are added. (B) "Type I design" Type I transmembrane chimeric co-receptors design is build on the type I structure on the natural co-receptors ICOS, CD28 and 41BB.

To test if the design of all chimeras allows correct folding and expression, Jurkat 76 cells, that had been previously transduced and selected to express the yठTCR-Cl5, were used to transduce the different NKG2D chimera constructs. Expression of both, NKG2Dchimeras and yסTCR-Cl5, was assessed by FACS (Figure 2A). Interestingly, large differences in surface expression of the chimeric co-receptors were observed between type II and type I chimeras. For the type II designs only one of the constructs (NKG2D-41BB) was marginally expressed. By contrast, all type I designs were expressed in Jurkat76. However, expression levels differed between the different type I chimeras, NKG2DCD28 wt was the one that showed best expression. The observed difference in expression 
was also still observed when cells have been purified by MACS sort using a NKG2D antibody (Figure 2B), suggesting a different expression strength presumably mediated through differences in linker and transmembrane domains between all type I design.

\section{A Type II}

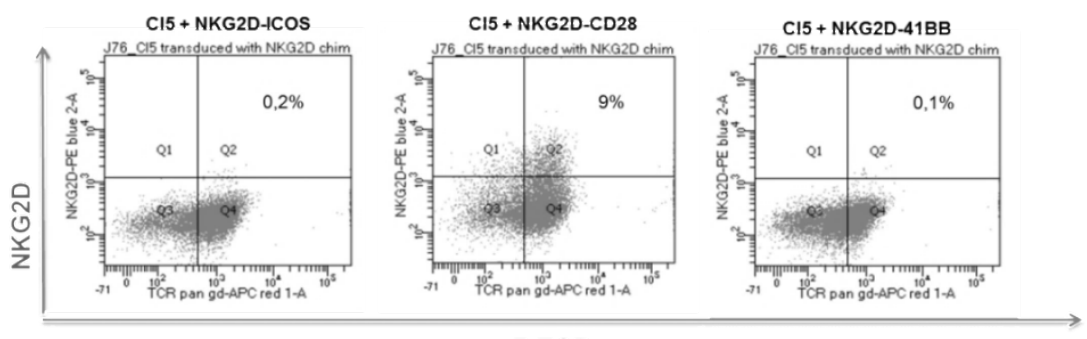

\section{Type I}

Y $\delta-T C R$

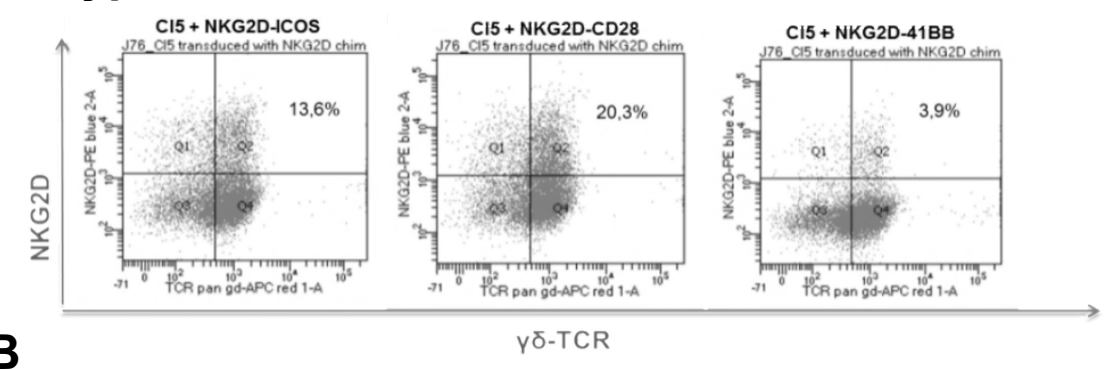

B

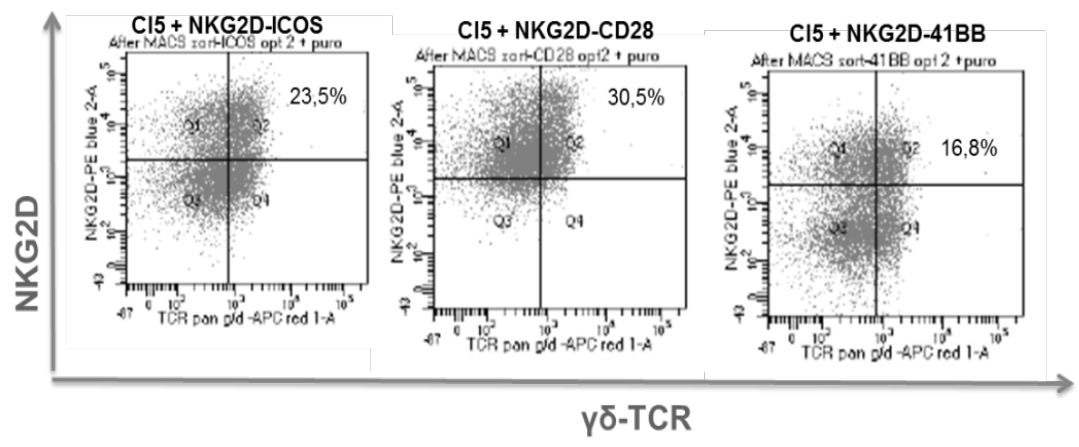

Figure 2. Surface expression of NKG2D chimeric co-receptors and yoTCR-Cl5 in Jurkat-76. (A) Surface expression of $ү \delta T C R-C l 5$ and type II and type I chimeras (B) Surface expression of $y \delta T C R-$ $\mathrm{Cl} 5$ and type I NKG2D chimeras after MACS sort selection using anti-NKG2D-PE and PE-microbeads.

Introduction of NKG2D-CD28 chimera in Jurkat-76 transduced with vठTCR-Cl5 increases percentage of CD69 expressing cells

To asses if the chimeras were able to increase the activity of the Jurkats-76 transduced with y $\delta T C R-C l 5$ and the type I NKG2D chimeras, we performed a CD69 assay. Firstly, 
we typed target cells for NKG2D ligand expression. Target cell lines were selected according to their susceptibility to be recognized by $\gamma \delta T C R-C l 5$ to serve as susceptible (K562, RPMI 8226, Daudi) or resistant (HL60) to TEG therapies [4, 10-13]. NKG2D ligand expression has been reported for most of these cell lines for individual ligands by us [4]. Recognition of K562, RPMI 8226, Daudi and HL60 cell lines by үסTCR-Cl5 has been previously reported and assessed in the lab. However as 8 different ligands can be bound NKG2D and we were interested in the additive effect of ligand expression to NKG2D binding, we determined the NKG2D-ligand expression by FACS using a NKG2D-Fc fusion protein. According to its susceptibility to be recognized by $ү \delta T C R-C l 5$ and the expression of NKG2D ligands, we were able then to distinguish three types of cell lines, one that was recognized by yరTCR-Cl5 but expressed limited levels of NKG2D ligands (Daudi), a second one that was targeted by YסTCR-Cl5 and expressed high levels of NKG2D ligands (K562 and RPMI 8226) and a third one that was not recognized by үסTCR-Cl5 but expressed high levels of NKG2D ligands (HL60) (Figure 3).
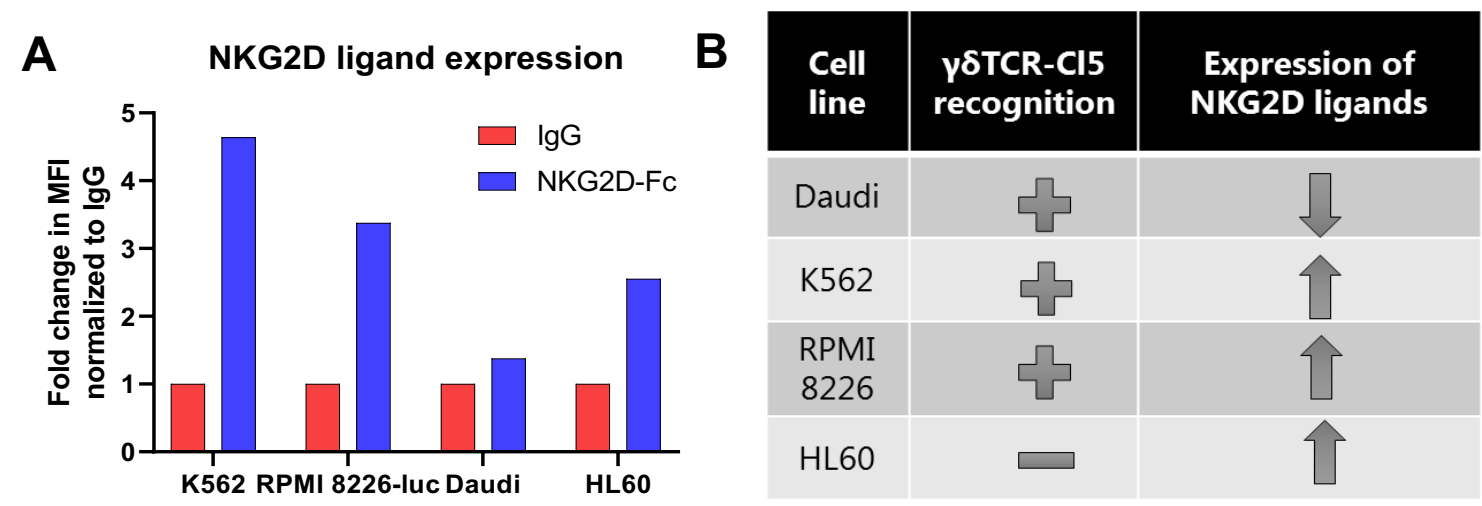

Figure 3. NKG2D ligand expression. (A) Surface expression of NKG2D ligands in Daudi, K562, RPMI 8226 and HL60, as assesed by flow cytometry (B) Summary of gdTCR-Cl5 recognition and NKG2D ligand expression in Daudi, K562, RPMI 8226 and HL60.

To assess activity of engineered Jurkat cells with or without engineered type I NKG2D chimera $10^{5}$ effector cells were co-cultured with $2 \times 10^{5}$ target cells overnight, in presence or absence of $100 \mu \mathrm{M}$ pamidronate. Introduction of the different chimeras in Jurkat-76 cells did not increase the percentage of CD69+ cells compared to cells transduced with y $\delta T C R-C l 5$ alone when they were co-culture together with HL60 (results comparable to 
no target condition) and Daudi (Fig. 4). However, an increase in CD69 positive cells was observed when cells co-transduced with yסTCR-Cl5 and NKG2D-CD28 ${ }_{\text {wt }}$ were cocultured together with $\mathrm{K} 562$, suggesting that this additional effect provided by the chimera only occurs in presence of NKG2D ligands in combination with TCR activation, as no increase was observed against other cell lines like Daudi, which expresses low NKG2D ligand levels or HL60 which despite high levels of NKG2D ligands is not recognized by yסTCR-Cl5. However, we could not exclude at this stage that increased activity is a consequence of increased expression or an altered signaling between different constructs

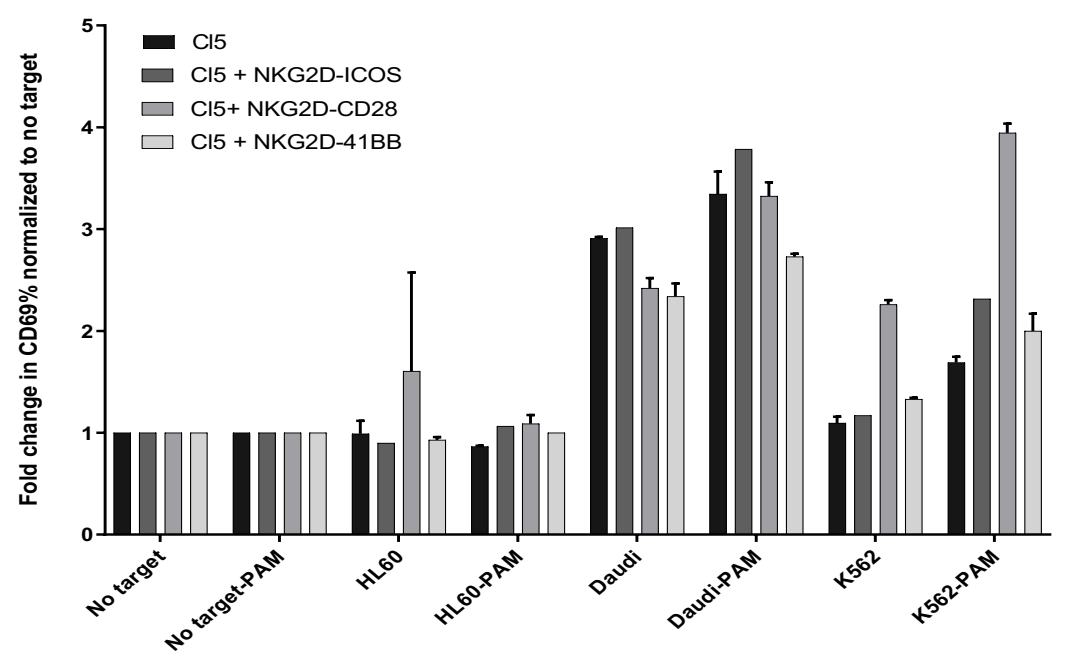

Figure 4. CD69 expression in transduced Jurkat-76. Percentage of CD69 positive cells was assessed by flow cytometry in Jurkat-76 cells transduced with gdTCR-Cl5 alone or gdTCR-Cl5 and the different type I chimeras after co-culturing with K562, RPMI 8226 and HL60.

\section{Equal expression of the chimeras by introducing CD28 transmembrane and linker} domains.

To assess whether differences in expression of type I NKG2D chimera is a general phenomena and to compare expression profile to engineered NKG2D $D_{w t}$, primary PBMC were engineered with $y 9 \delta 2 T C R, N K G 2 D_{w t}$ and type I variants. In order to avoid that unequal expression is a consequence of different transduction efficacy of separate constructs, NKG2D $D_{\text {wt }}$ or three type I NKG2D chimeras were cloned together with the yठTCR-Cl5 into the clinical vector pmp71 (Figure 5A). PBMCs were transduced using these constructs. Expression of the three chimeric receptors and $y \delta T C R-C l 5$ was 
assessed by FACs (Fig. 5B). Introduction of exogenous NKG2 $D_{w t}$ further increased natural NKG2D expression as well as introduction of type I NKG2D chimera. However, again the expression level of the NKG2D-CD28 ${ }_{\text {wt }}$ chimera was stronger when compared to the other two chimeras and NKG2D $\mathrm{w}_{\mathrm{wt}}$.

A

\begin{tabular}{l|l|l|l|l|l|l|l|}
\hline TCRY & T2A & TCRD & P2A & SP & NKG2D EC & ICOS H + TM & ICOS CP \\
\hline TCRY & T2A & TCRD & P2A & SP & NKG2D EC & CD28 H + TM & CD28 CP \\
\hline TCRY & T2A & TCR & P2A & SP & NKG2D EC & 41BB H + TM & 41BB CP \\
\hline
\end{tabular}

B
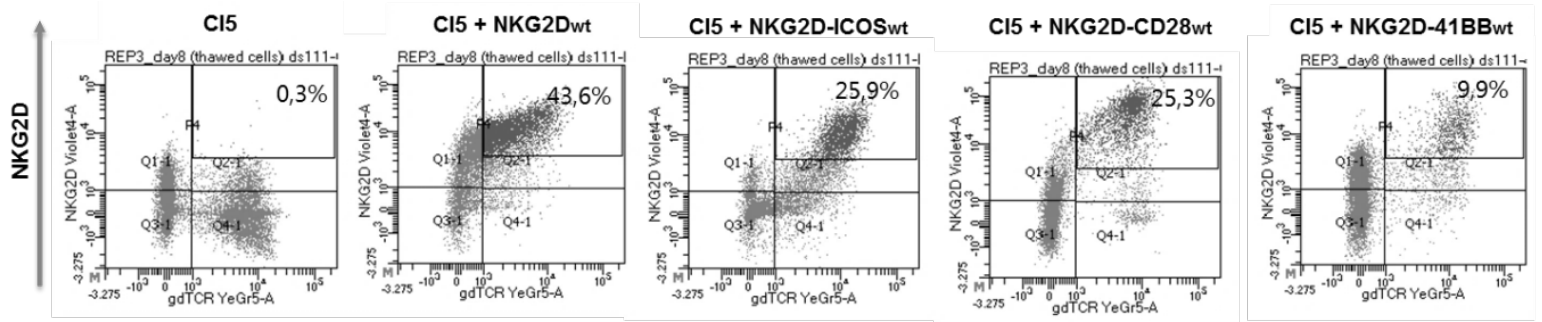

үठ TCR

Figure 5. Unequal expression of type I chimeras in PBMCs (A) Schematic overview of three different type I chimeras and gdTCR transgene cassette in the retroviral vector pMP71. TCR $\delta$ chain was derived from clone 5 (d) and TCRy from clone G115 (g) and F2A (derived from the foot-andmouth disease virus) and T2A (derived from the Thosea asigna virus) refer to two different $2 \mathrm{~A}$ ribosomal skipping sequences. (B) Surface expression of gdTCR-Cl5 and type I NKG2D chimeric coreceptors in Jurkat-76 cells assessed by flow cytometry.

Strength of membrane expression of proteins can depend on their transmembrane domain [13]. NKG2D-CD28 ${ }_{w t}$ chimera expression was a consequence of its superior transmembrane domain. Therefore we next swapped the transmembrane and linker domains of the NKG2D-ICOS ${ }_{w t}$ and NKG2D-4-1BB wt $_{w t}$ for the transmembrane and linker domains of the NKG2D-CD28 ${ }_{\text {wt }}$ chimera (Figure 6A). The new chimeras were cloned together with the YठTCR-Cl5 or YठTCR-LM1 (mock) into the clinical vector pmp71 (Figure 6B). Again PBMCs were transduced using these constructs. $\gamma \delta T C R-L M 1$ and $\gamma \delta T C R-C l 5$ with NKG2D wt $_{\text {or NKG2D-CD28 }}$ wt chimera were also taken along as controls. Expression of the three chimeras and $ү \delta T C R-C l 5$ or $ү \delta T C R-L M 1$ was assessed by FACs (Figure 6C). 
The expression of the new chimeras (NKG2D-ICOS ${ }_{\mathrm{CD} 28 T M}$ and NKG2D-4-1BB ${ }_{\mathrm{CD} 28 T \mathrm{TM}}$ ) was now improved by replacing the transmembrane and linker domains by those of CD28, and it was equal to the NKG2D-CD28 ${ }_{\text {wt }}$ chimera. In all cases, the expression of the chimeras was better compared to NKG2D $D_{\text {wt. }}$

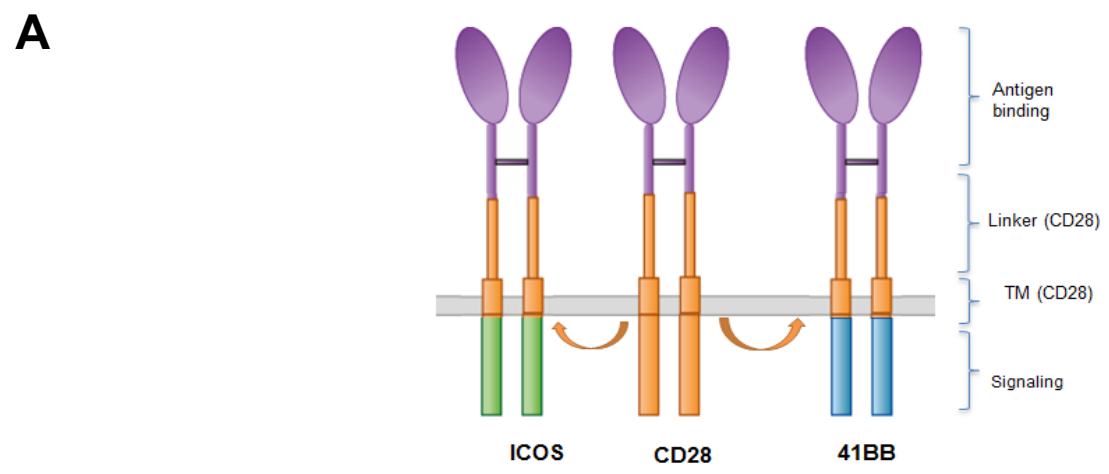

B

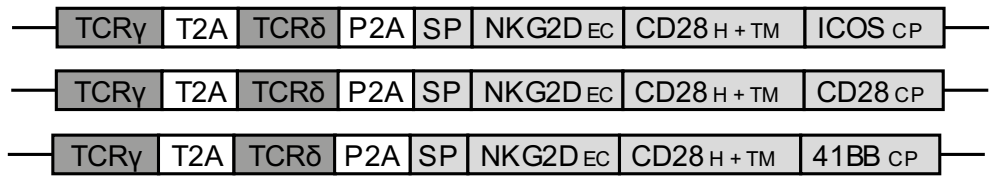

C
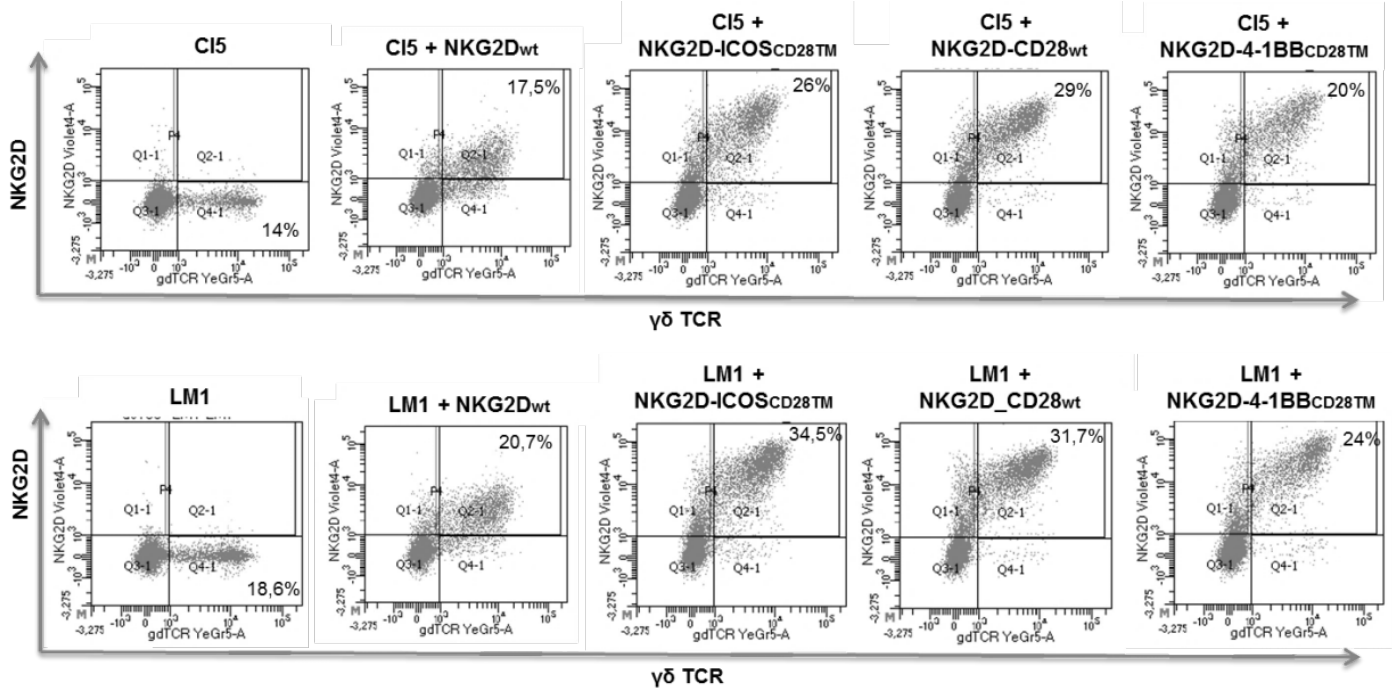

Figure 6. Introduction of CD28 transmembrane and linker domains increases the expression of type I designs of NKG2D-ICOS and NKG2D-4-1BB chimeric co-receptors (A) Schematic diagram of the new type I chimeras containing CD28 transmembrane and linker domains (B) Schematic overview of new type I chimeras generated and gdTCR transgene cassette in the retroviral vector pMP71. (C) Surface expression of gdTCR-Cl5 and new NKG2D chimeric co-receptors in Jurkat-76 cells assessed by flow cytometry. 
Introduction of NKG2D-41BB increases cytokine release by TEG001 in presence of NKG2D ligands

In order to assess whether adding exogenous NKG2D $D_{\text {wt }}$ to TEGs increases activity of TEGs or whether adding type I chimeras would be superior, we performed an IFNY release assay. As the NKG2D receptor is naturally expressed by many CD8+ $\alpha \beta T$ cells, CD4+ $\alpha \beta T$ cells were used as effector cells. CD4+ transduced cells were co-cultured with K562 (high levels of NKG2D ligands and recognized by yסTCR-Cl5), Daudi (low levels of NKG2D ligands but recognized by үסTCR-Cl5) and HL60 (high levels of NKG2D ligands but not recognized by y $\delta T C R-C l 5)$. Pamidronate was used at different concentrations to increase the levels of phosphoantigens in the target cells and therefore increase the recognition of these cells by yסTCR-CI5.

The most prominent change was observed for cells co-transduced with y $\delta \mathrm{TCR}-\mathrm{Cl} 5$ and the NKG2D-4-1BB СD28тм which secreted higher levels of IFNg against NKG2D-ligand high expression tumor cells K562 when compared with the TEGs that only expressed $\gamma \delta T C R-$ $\mathrm{Cl} 5$ (Figure 7). In addition, in this particular combination of TEGs with NKG2D-4$1 \mathrm{BB}_{\mathrm{CD} 28 \mathrm{TM}}$, engineered immune cells were also able to recognize NKG2D high expressing tumor cells K562 at lower pamidronate concentrations when compared to all other conditions. This increase was not observed when T cells were co-transduced with a nonfunctional yठTCR (LM1). Furthermore, this increase in IFNg release was not observed against Daudi (low levels of NKG2D ligands) or HL60 (not recognized by үסTCR-Cl5), suggesting that both signals (TCR activation and NKG2D ligands) are needed to induce activation of the chimera, and which is in line with the results obtained using Jurkats. This emphasized also the need to compare engineered with equivalent receptor expression, as this signal was missed in Jurkat cells when using NKG2D domains with 4-1-BB transmembrane and signaling domain. We could also not rule out that enhanced NKG2 $D_{\text {wt }}$ expression might have similar effects, however in the wt design the expression level was limited and always inferior when compared to chimeras using CD28 transmembrane domains. 
HL60

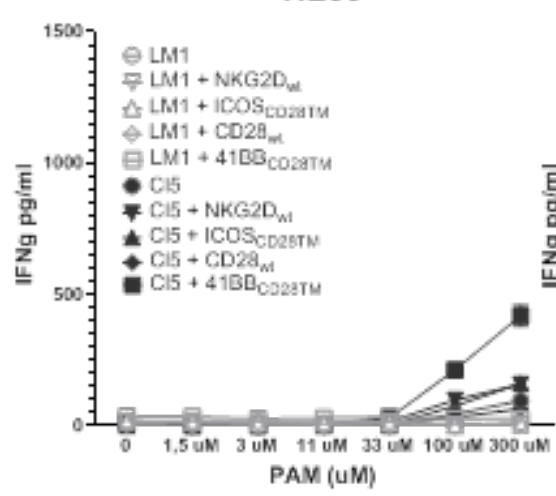

Daudi

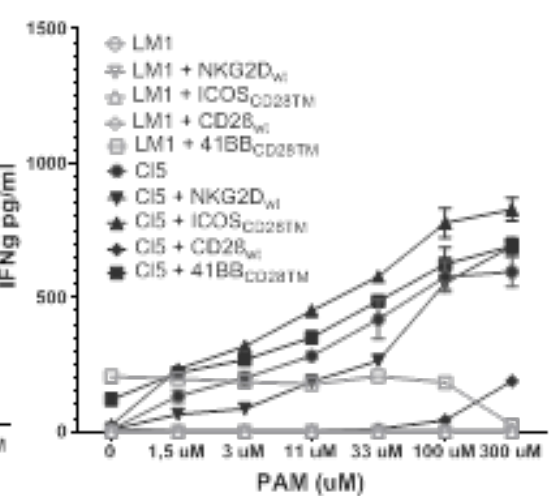

K562

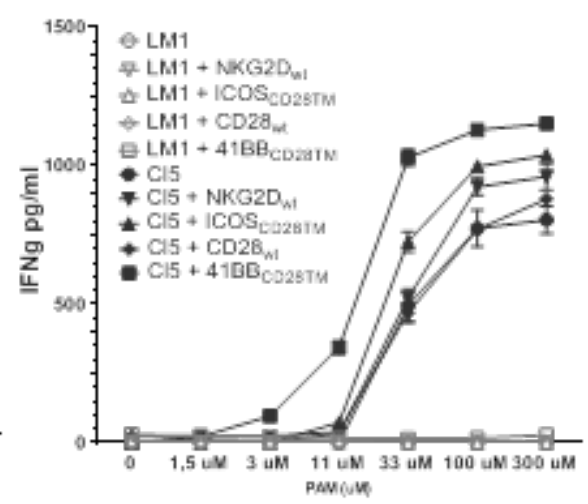

Figure 7. Introduction of NKG2D-4-1BB chimeric co-receptor increases IFNY release by TEG001. Transduced T cells were incubated with K562, HL60 or Daudi at several pamidronate concentrations. After 18 hours, supernatants were harvested and analyzed for IFNY secretion by ELISA.

\section{Introduction of NKG2D-41BB and NKG2D-CD28 increases killing and proliferation} ability of TEG001

Next, we aimed to asses whether the NKG2D type I chimeras with the CD28 transmembrane domain were able to increase the killing ability of TEGs. Therefore, $T$

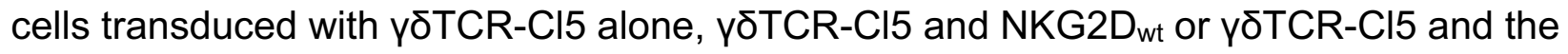
different type I chimeras with the CD28 transmembrane domain were co-cultured with RPMI-8226 tumor cells expressing luciferase, in presence or absence of pamidronate. Co-culture was made using different effector-target ratios. After incubation, luciferin was added to the wells and signal was measured.

A mixture of $\mathrm{CD}^{+}(75 \%)$ and $\mathrm{CD}^{+}(25 \%) \alpha \beta$ T cells co-transduced with $\gamma \delta T C R-C l 5$ and the chimeras NKG2D-CD28 ${ }_{\text {wt }}$ and NKG2D-4-1BB ${ }_{C D 28 T M}$ showed increased killing ability compared to yठTCR-Cl5 alone (Fig. 8). This increase in killing ability was especially remarkable at lower E:T ratios and was not observed in T cells co-transduced with mock Y $\delta T C R ~(L M 1)$ and the different NKG2D chimeras. Furthermore, cells co-transduced with y $\delta T C R-C l 5$ and NKG2D wt also showed an increment in killing compared to y $\delta T C R-C l 5$ alone. However, also an increase in specific lysis was observed when NKG2D wt was cotransduced with yठTCR-LM1 (mock). 

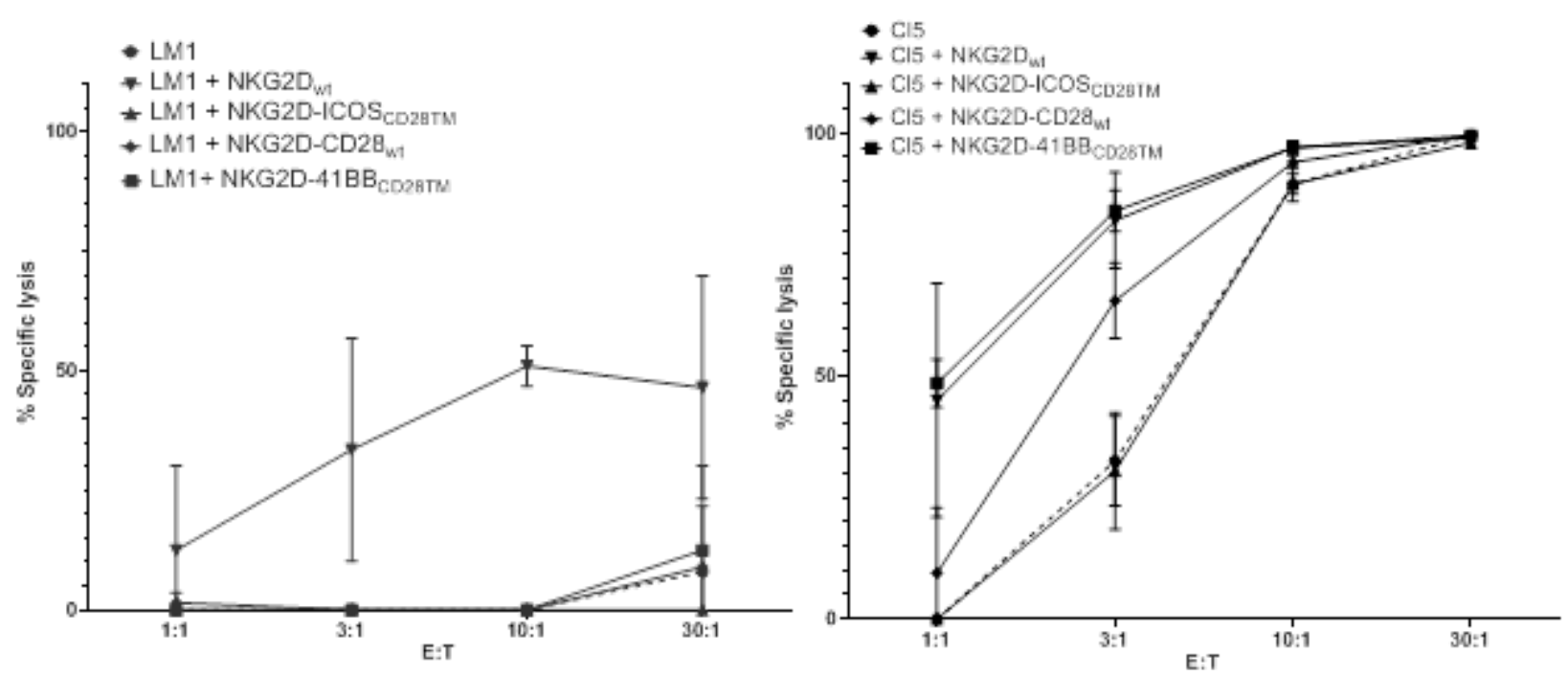

Figure 8. Introduction of NKG2D-4-1BB chimeric co-receptor increases killing ability of TEG001. Transduced T cells were incubated with RPMI 8226-luc+ cells in presence of $10 \mu \mathrm{M}$ PAM. Specific lysis was calculated using the formula $\%$ specific lysis $=100 \times$ [(experimental data-spontaneous cell death $) /($ maximum cell death - spontaneous cell death)]. When this calculation provided a negative value, $0 \%$ was assigned as the result.

\section{Introduction of NKG2D chimeras improves proliferation capacity of TEG001}

Different co-stimulatory domains have been reported to mainly affect proliferation capacity. Therefore we examined proliferation capacity of TEGs transduced with NKG2D $D_{\text {wt }}$ and the different type I NKG2D chimeras with CD28 transmembrane domains by using a dye dilution approach. Again CD4+ $\alpha \beta T$ cells selected cells were used as it allowed also to assess the additional impact of NKG2D $D_{\text {wt. }}$ They were fluorescently labeled using Cell Trace violet dye and co-cultured either with HL60 (NKG2D ligand negative) or RPMI-8226 (NKG2D ligand positive) tumor cells in presence of $100 \mu \mathrm{M}$ pamidronate. After 6 days, cells were analyzed by flow cytometry. As expected, cells transduced with YठTCR-LM1 (mock) were not able to proliferate when co-cultured together with tumor cells (Figure 9). Moreover, the introduction of NKG2 $D_{w t}$ did not change the proliferation rate compared to $T$ cells transduced with yठTCR-Cl5 alone or when NKG2D $D_{\text {wt }}$ was expressed. In contrast TEGs coexpressing three different type I chimeras with the CD28 transmembrane domain showed an improved proliferation capacity as indicated by the lower CTV intensity. Furthermore, this increase in proliferation was only observed when 
T cells were co-cultured together with RPMI 8226, but not with HL60. As both, RPMI 8226 and HL60 are expressing high levels of NKG2D ligands, but only RPMI-8226 is recognized by $\gamma \delta T C R-C l 5$, these data suggest that $ү 9 \delta 2 T C R$ activation is essential for any additive effect of the chimeras.

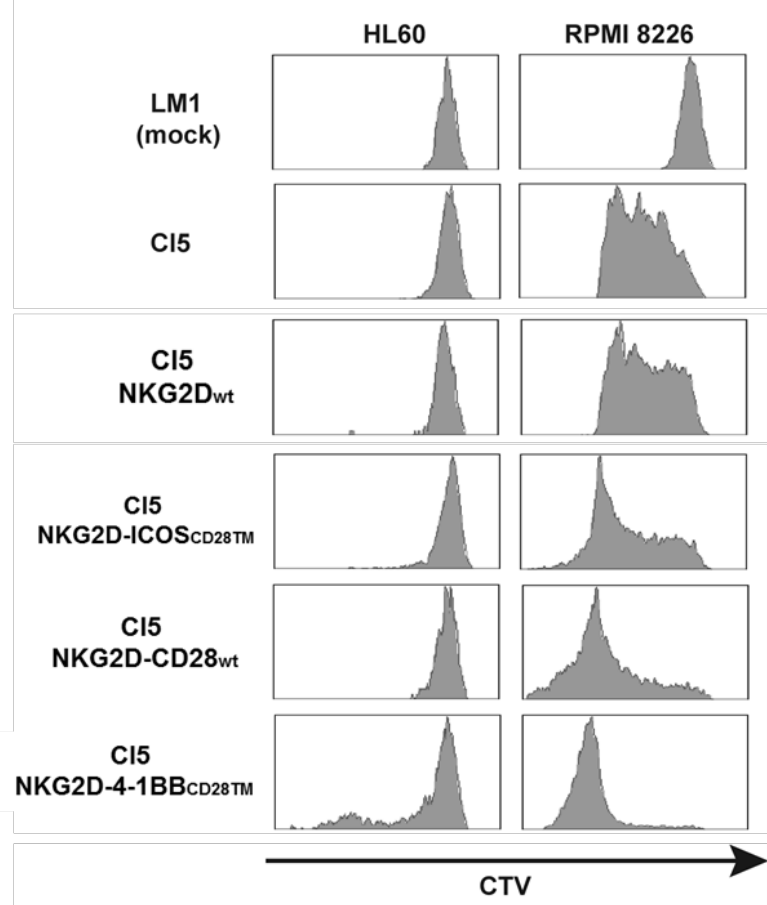

Figure 9. Introduction of NKG2D chimeric co-receptors improves proliferation ability of TEG001. Transduced T cells were incubated either with HL60 or RPMI 8226 cells in presence of $100 \mu \mathrm{M}$ PAM. On day 6 CTV intensity was assessed by flow cytometry.

\section{Discussion}

Different chimeras were designed in this project, by fusing the extracellular domain of NKG2D to the cytoplasmic domain of three different costimulatory proteins (ICOS, CD28, 4-1BB). According to the orientation of the proteins, type II and type I chimeras were designed. Only chimeras with a type I orientation were expressed. However, expression between type I chimeras was unequal when the transmembrane and linker domains of the different costimulatory proteins were used, with NKG2D-CD28 $8_{\text {wt }}$ chimera always be the best expressed when compared to NKG2D-ICOS ${ }_{w t}$ and NKG2D-4-1BB ${ }_{w t}$. To improve 
expression of other chimeras, swapping the transmembrane and linker domains of NKG2D-ICOS and NKG2D-4-1BB by NKG2D-CD28's domains was explored (NKG2DICOS ${ }_{C D 28 T M}$ and NKG2D-4-1BB ${ }_{C D 28 T M}$ ). This modification increased the expression of both chimeras and equaled the expression between all of the chimeras.

Cells co-transduced with y $\delta T C R-C l 5$ and the three chimeras were tested in different functional assays and compared with cells transduced with yరTCR-Cl5 alone (TEG001). Altogether, these results suggest that the introduction of NKG2D-CD28 $8_{w t}$ and NKG2D-4$1 \mathrm{BB}_{\mathrm{CD} 28 \mathrm{TM}}$ increase the activity of TEG001.

1. Sebestyen, Z., et al., Translating gammadelta (gammadelta) $T$ cells and their receptors into cancer cell therapies. Nat Rev Drug Discov, 2020. 19(3): p. 169-184.

2. Hartmann, J., et al., Clinical development of CAR T cells-challenges and opportunities in translating innovative treatment concepts. EMBO Mol Med, 2017. 9(9): p. 1183-1197.

3. Teixeiro, E., et al., Different T Cell Receptor Signals Determine CD8+ Memory Versus Effector Development. Science, 2009. 323(5913): p. 502-505.

4. Marcu-Malina, V., et al., Redirecting alphabeta $T$ cells against cancer cells by transfer of $a$ broadly tumor-reactive gammadeltaT-cell receptor. Blood, 2011. 118(1): p. 50-59.

5. Liu, H., et al., Role of NKG2D and its ligands in cancer immunotherapy. Am J Cancer Res, 2019. 9(10): p. 2064-2078.

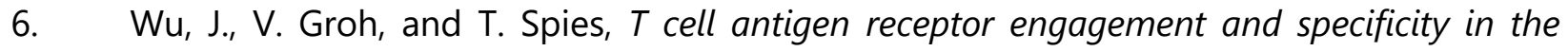
recognition of stress-inducible $M H C$ class I-related chains by human epithelial gamma delta $T$ cells. J.Immunol., 2002. 169(3): p. 1236-1240. 
7. Baumeister, S.H., et al., Phase I Trial of Autologous CAR T Cells Targeting NKG2D Ligands in Patients with AML/MDS and Multiple Myeloma. Cancer Immunol Res, 2019. 7(1): p. 100112.

8. Rincon-Orozco, B., et al., Activation of $\mathrm{V}$ gamma $9 \mathrm{~V}$ delta $2 \mathrm{~T}$ cells by NKG2D. J.Immunol., 2005. 175(4): p. 2144-2151.

9. $\quad$ Orr, M.T. and L.L. Lanier, Natural killer cell education and tolerance. Cell, 2010. 142(6): p. 847-56.

10. Vyborova, A., et al., gamma9delta2T cell diversity and the receptor interface with tumor cells. J Clin Invest, 2020.

11. Johanna, I., et al., Evaluating in vivo efficacy - toxicity profile of TEG001 in humanized mice xenografts against primary human AML disease and healthy hematopoietic cells. J Immunother Cancer, 2019. 7(1): p. 69.

12. Straetemans, T., et al., Untouched GMP-Ready Purified Engineered Immune Cells to Treat Cancer. Clin Cancer Res, 2015. 21(17): p. 3957-68.

13. Grunder, C., et al., gamma9 and delta2CDR3 domains regulate functional avidity of $T$ cells harboring gamma9delta2TCRs. Blood, 2012. 120(26): p. 5153-5162.

13. Fujiwara, K., et al., Hinge and Transmembrane Domains of Chimeric Antigen Receptor Regulate Receptor Expression and Signaling Threshold. Cells, 2020. 9(5): 1182 


\section{Supplementary figure 1}

A
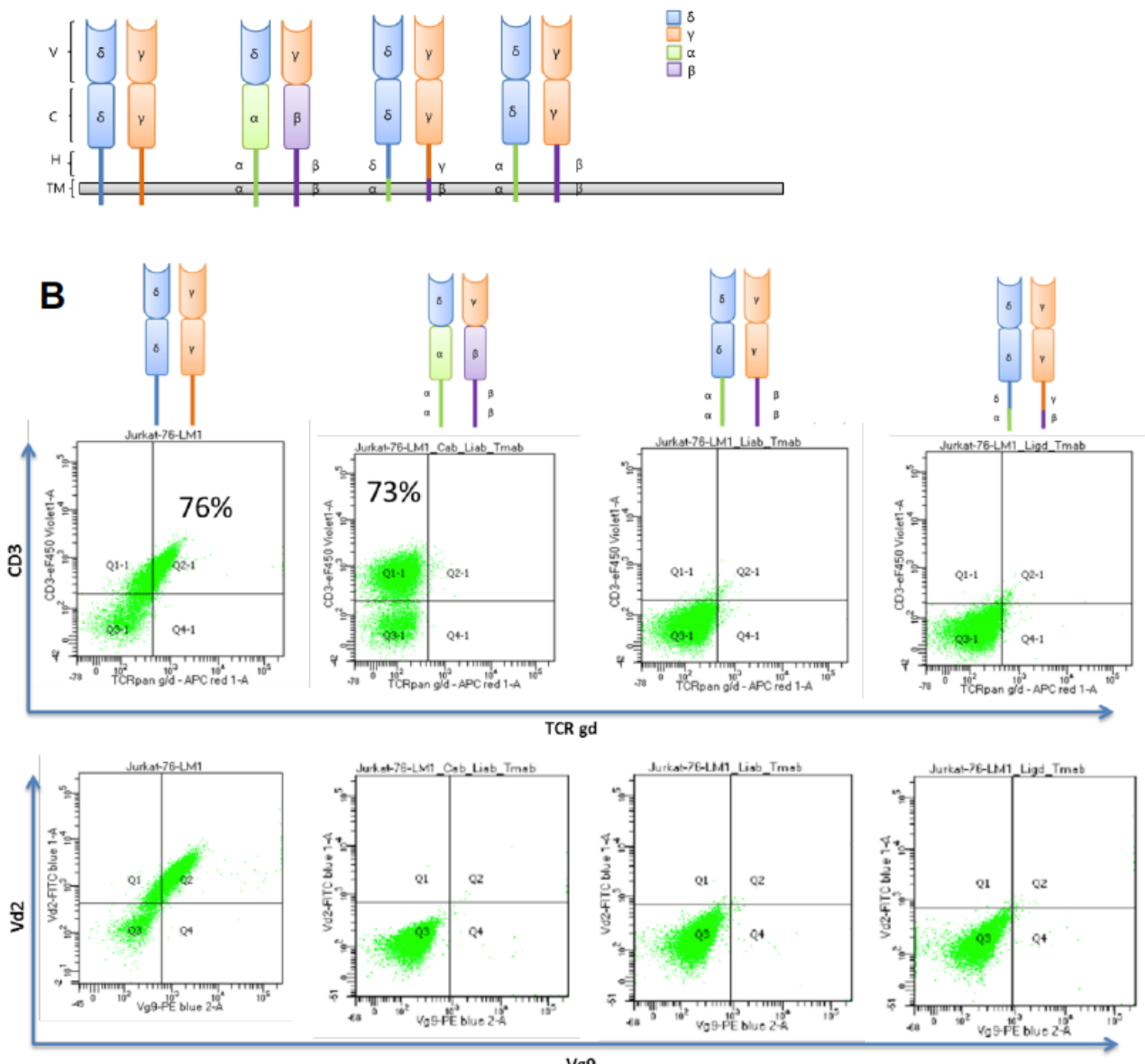

Vg9

\section{C}

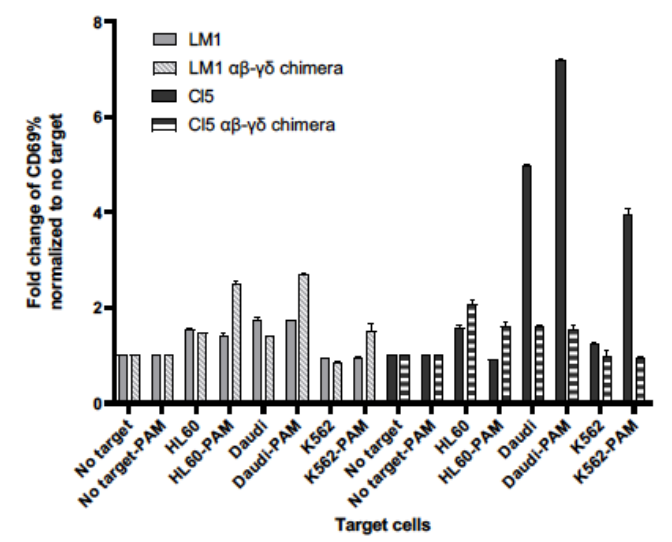

Supplementary figure 1. First version of $\alpha \beta-\gamma \delta$ TCR chimeras (A) Schematic overview of three different $\alpha \beta-$ үठ TCR chimeras. (V) variable, (C) constant, (H) hinge and (TM) transmembrane domains from $\alpha \beta$ or $ү \delta$ TCRs were used (B) Surface expression of $\alpha \beta-\gamma \delta$ TCR chimeras in Jurkat-76 cells assessed by flow cytometry. (C) Percentage of CD69 positive cells was assessed by flow cytometry in Jurkat-76 cells transduced with gdTCRCl5, gdTCR-LM1 (mock) or dfferent $\alpha \beta-\gamma \delta$ TCR chimeras after co-culturing alone or with K562, Daudi and HL60. 


\section{Supplementary figure 2}

A
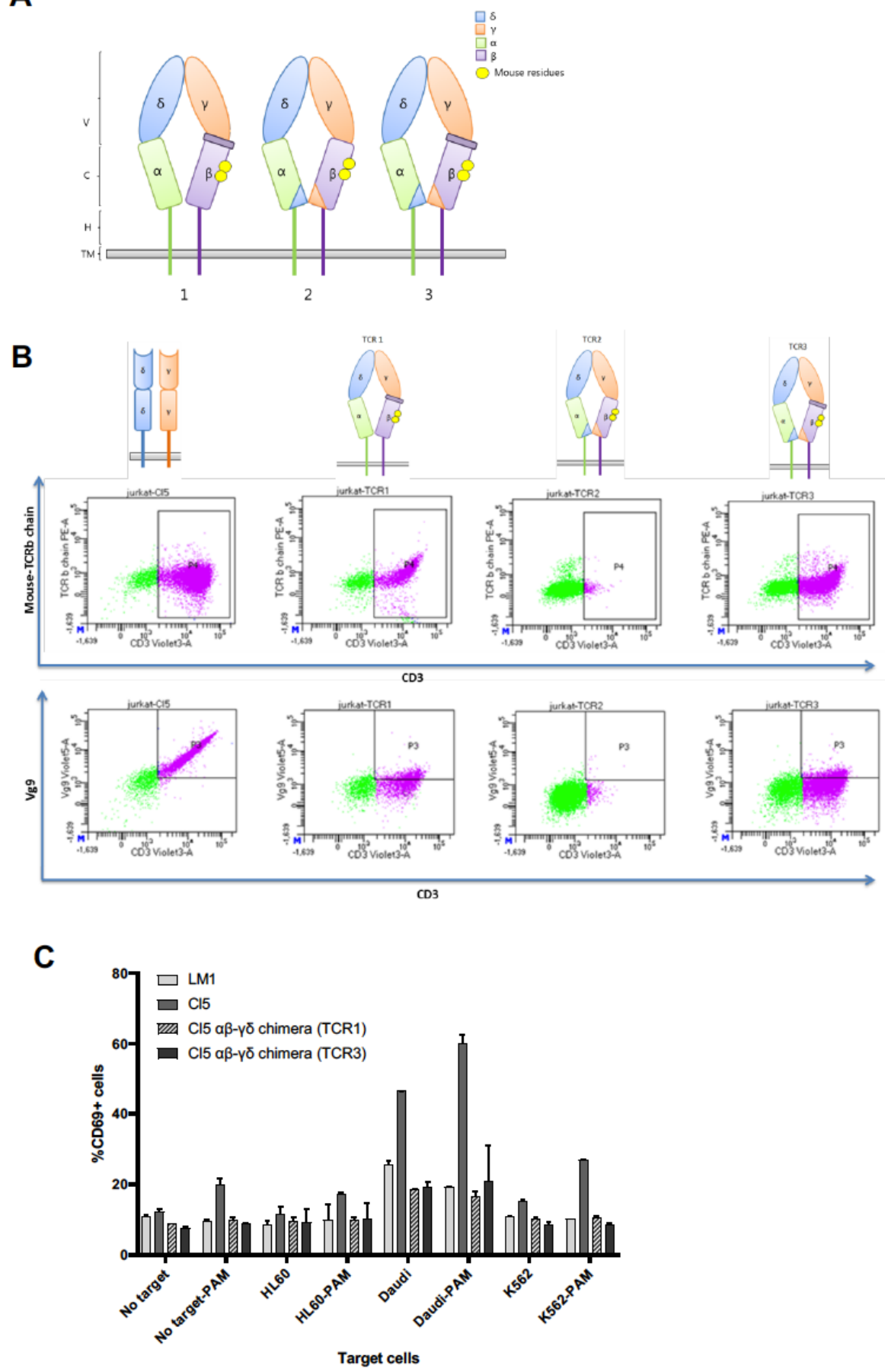

Supplementary figure 2. Second version of $\alpha \beta-\gamma \delta$ TCR chimeras (A) Schematic overview of the second version of three different $\alpha \beta-\gamma \delta$ TCR chimeras. (V) variable, (C) constant, (H) hinge and (TM) transmembrane domains from $\alpha \beta$ or $\gamma \delta$ TCRs were used (B) Surface expression of the second version of $\alpha \beta-\gamma \delta$ TCR chimeras in Jurkat-76 cells assessed by flow cytometry. (C) Percentage of CD69 positive cells was assessed by flow cytometry in Jurkat-76 cells transduced with gdTCR-Cl5, gdTCR-LM1 (mock) or $\alpha \beta-\gamma \delta \overline{T C R}$ chimera named as 1 and 3 after co-culturing alone or with K562, Daudi and HL60. 


\section{Appendix}

\begin{tabular}{|c|c|c|}
\hline Construct name & DNA sequence & $\begin{array}{l}\text { Amino acid } \\
\text { sequence }\end{array}$ \\
\hline $\begin{array}{c}\text { Type II: } \\
\text { 4-1BBcyto-NKG2D tm + ec }\end{array}$ & $\begin{array}{l}\text { CTGCCATGGGTAAGCGGGGCAGAAAGAAGCTGCTG } \\
\text { TACATCTTCAAGCAGCCCTTCATGCGGCCCGTGCAG } \\
\text { ACCACACAAGAGGAAGATGGCTGCTCCTGCAGATT } \\
\text { CCCCGAGGAAGAAGAAGGCGGCTGCGAGCTGCCC } \\
\text { TTCTTTTTCTGCTGCTTTATCGCCGTGGCAATGGGCA } \\
\text { TCCGCTTCATCATTATGGTGGCTATTTGGAGCGCCG } \\
\text { TGTTCCTGAACTCCCTGTTCAATCAAGAGGTGCAGA } \\
\text { TCCCTCTGACCGAGAGCTACTGTGGCCCCTGTCCTA } \\
\text { AGAACTGGATCTGCTACAAGAACAACTGCTACCAG } \\
\text { TTCTTCGACGAGAGCAAGAATTGGTACGAGAGCCA } \\
\text { GGCCAGCTGCATGAGCCAGAATGCCAGCCTGCTGA } \\
\text { AGGTGTACTCCAAAGAGGACCAGGATCTGCTGAAG } \\
\text { CTGGTCAAGAGCTACCACTGGATGGGCCTCGTGCA } \\
\text { CATCCCTACCAATGGCTCTTGGCAGTGGGAGGACG } \\
\text { GCAGCATTCTGAGCCCTAACCTGCTGACCATCATCG } \\
\text { AGATGCAGAAGGGCGACTGCGCCCTGTACGCCAGC } \\
\text { AGCTTTAAGGGCTACATCGAGAACTGCAGCACCCCT } \\
\text { AACACCTACATCTGTATGCAGCGGACCGTCTGAGG } \\
\text { ATCC }\end{array}$ & $\begin{array}{l}\text { MGKRGRKKLLYIFKQP } \\
\text { FMRPVQTTQEEDGCS } \\
\text { CRFPEEEEGGCELPFFF } \\
\text { CCFIAVAMGIRFIIMVAI } \\
\text { WSAVFLNSLFNQEVQI } \\
\text { PLTESYCGPCPKNWIC } \\
\text { YKNNCYQFFDESKNW } \\
\text { YESQASCMSQNASLLK } \\
\text { VYSKEDQDLLKLVKSY } \\
\text { HWMGLVHIPTNGSW } \\
\text { QWEDGSILSPNLLTIIE } \\
\text { MQKGDCALYASSFKG } \\
\text { YIENCSTPNTYICMQRT } \\
\text { V- }\end{array}$ \\
\hline $\begin{array}{c}\text { Type II: } \\
\text { CD28cyto-NKG2D tm (18 nt) }\end{array}$ & $\begin{array}{l}\text { ATTCCATGGGTAGAAGCAAGCGGAGCAGACTGCTG } \\
\text { CACAGCGACTACATGAACATGACCCCTAGACGGCC } \\
\text { CGGACCTACCAGAAAGCACTACCAGCCTTACGCTC } \\
\text { CTCCTAGAGACTTCGCCGCCTACAGAAGCCCCTTCT } \\
\text { TTTTCTGCTGC }\end{array}$ & $\begin{array}{l}\text { MGRSKRSRLLHSDYM } \\
\text { NMTPRRPGPTRKHYQ } \\
\text { PYAPPRDFAAYRSPFFF } \\
\text { CC }\end{array}$ \\
\hline $\begin{array}{c}\text { Type II: } \\
\text { ICOScyto-NKG2D tm (18 nt) }\end{array}$ & $\begin{array}{l}\text { TTTCCATGGGTTGCTGGCTGACCAAGAAAAAGTACA } \\
\text { GCAGCAGCGTGCACGACCCCAACGGCGAGTACATG } \\
\text { TTCATGAGAGCCGTGAACACCGCCAAGAAGTCCAG } \\
\text { ACTGACAGACGTGACCCTGCCCTTCTTTTTCTGCTGC }\end{array}$ & $\begin{array}{l}\text { MGCWLTKKKYSSSVH } \\
\text { DPNGEYMFMRAVNTA } \\
\text { KKSRLTDVTLPFFFCC }\end{array}$ \\
\hline $\begin{array}{l}\text { Type I: } \\
\text { CD33_NKG2D_linker_ } \\
\text { ICOStm + cyto }\end{array}$ & $\begin{array}{l}\text { CCATGGCTCTGCTGCTGCTTCTGCCTCTTCTGTGGGC } \\
\text { TGGTGCTCTGGCTATGGAGAGCTACTGTGGCCCCTG } \\
\text { TCCTAAGAACTGGATCTGCTACAAGAACAACTGCTA } \\
\text { CCAGTTCTTCGACGAGAGCAAGAATTGGTACGAGA } \\
\text { GCCAGGCCAGCTGCATGAGCCAGAATGCCAGCCTG } \\
\text { CTGAAGGTGTACAGCAAAGAGGACCAGGATCTGCT } \\
\text { GAAGCTGGTCAAGAGCTACCACTGGATGGGCCTCG } \\
\text { TGCACATCCCTACCAATGGCTCTTGGCAGTGGGAG } \\
\text { GACGGCAGCATTCTGAGCCCTAACCTGCTGACCATC } \\
\text { ATCGAGATGCAGAAGGGCGACTGCGCCCTGTACGC } \\
\text { CAGCAGCTTTAAGGGCTACATCGAGAACTGCAGCA } \\
\text { CCCCTAACACCTACATCTGTATGCAGCGGACCGTCA } \\
\text { GCCAGCTGTGCTGCCAGCTGAAGTTCTGGCTGCCCA } \\
\text { TCGGCTGCGCCGCCTTCGTGGTGGTGTGCATCCTGG } \\
\text { GCTGCATCCTGATCTGCTGGCTGACCAAGAAAAAGT } \\
\text { ACAGCAGCAGCGTGCACGACCCCAACGGCGAGTAC } \\
\text { ATGTTCATGAGAGCCGTGAACACCGCCAAGAAGTC } \\
\text { CAGACTGACAGACGTGACCCTGTGAGGATCC }\end{array}$ & $\begin{array}{l}\text { MALLLLLPLLWAGALA } \\
\text { MESYCGPCPKNWICYK } \\
\text { NNCYQFFDESKNWYE } \\
\text { SQASCMSQNASLLKV } \\
\text { YSKEDQDLLKLVKSYH } \\
\text { WMGLVHIPTNGSWQ } \\
\text { WEDGSILSPNLLTIIEM } \\
\text { QKGDCALYASSFKGYIE } \\
\text { NCSTPNTYICMQRTVS } \\
\text { QLCCQLKFWLPIGCAA } \\
\text { FVVVILGCILICWLTKK } \\
\text { KYSSSVHDPNGEYMF } \\
\text { MRAVNTAKKSRLTDVT } \\
\text { L- }\end{array}$ \\
\hline
\end{tabular}




\begin{tabular}{|c|c|c|}
\hline $\begin{array}{c}\text { Type I: } \\
\text { CD33_NKG2D_linker_ } \\
\text { CD28tm + cyto }\end{array}$ & $\begin{array}{l}\text { GCCATGGCCCTGCTGCTGCTTCTGCCTCTTCTTTGGG } \\
\text { CTGGCGCTCTGGCTATGGAGAGCTACTGTGGCCCCT } \\
\text { GTCCTAAGAACTGGATCTGCTACAAGAACAACTGCT } \\
\text { ACCAGTTCTTCGACGAGAGCAAGAATTGGTACGAG } \\
\text { AGCCAGGCCAGCTGCATGTCCCAGAATGCCAGCCT } \\
\text { GCTGAAGGTGTACAGCAAAGAGGACCAGGATCTGC } \\
\text { TGAAGCTGGTCAAGAGCTACCACTGGATGGGCCTC } \\
\text { GTGCACATCCCTACCAATGGCTCTTGGCAGTGGGA } \\
\text { GGACGGCAGCATTCTGAGCCCTAACCTGCTGACCA } \\
\text { TCATCGAGATGCAGAAGGGCGACTGCGCCCTGTAC } \\
\text { GCCAGCAGCTTTAAGGGCTACATCGAGAACTGCAG } \\
\text { CACCCCTAACACCTACATCTGTATGCAGCGGACCGT } \\
\text { GGGCAAGCACCTGTGCCCCAGCCCCTGTTCCCCG } \\
\text { GCCCCAGCAAGCCCTTCTGGGTGCTGGTGGTGGTG } \\
\text { GGCGGCGTGCTGGCCTGCTACAGCCTGCTGGTGAC } \\
\text { CGTGGCCTTCATCATCTTCTGGGTGAGAAGCAAGCG } \\
\text { GAGCAGACTGCTGCACAGCGACTACATGAACATGA } \\
\text { CCCCTAGACGGCCCGGACCTACCAGAAAGCACTAC } \\
\text { CAGCCTTACGCTCCTCCTAGAGACTTCGCCGCCTAC } \\
\text { AGAAGCTGAGGATCC }\end{array}$ & $\begin{array}{l}\text { MALLLLLPLLWAGALA } \\
\text { MESYCGPCPKNWICYK } \\
\text { NNCYQFFDESKNWYE } \\
\text { SQASCMSQNASLLKV } \\
\text { YSKEDQDLLKLVKSYH } \\
\text { WMGLVHIPTNGSWQ } \\
\text { WEDGSILSPNLLTIIEM } \\
\text { QKGDCALYASSFKGYIE } \\
\text { NCSTPNTYICMQRTVG } \\
\text { KHLCPSPLFPGPSKPF } \\
\text { WVLVVVGGVLACYSLL } \\
\text { VTVAFIIFWVRSKRSRL } \\
\text { LHSDYMNMTPRRPGP } \\
\text { TRKHYQPYAPPRDFAA } \\
\text { YRS- }\end{array}$ \\
\hline $\begin{array}{c}\text { Type I: } \\
\text { CD33_NKG2D_linker_ } \\
\text { 4-1BBtm + cyto }\end{array}$ & $\begin{array}{l}\text { CCATGGCTCTGCTGCTGCTTCTGCCTCTTCTGTGGGC } \\
\text { TGGTGCTCTGGCTATGGAGAGCTACTGTGGCCCCTG } \\
\text { TCCTAAGAACTGGATCTGCTACAAGAACAACTGCTA } \\
\text { CCAGTTCTTCGACGAGAGCAAGAATTGGTACGAGA } \\
\text { GCCAGGCCAGCTGCATGTCCCAGAATGCCAGCCTG } \\
\text { CTGAAGGTGTACAGCAAAGAGGACCAGGATCTGCT } \\
\text { GAAGCTGGTCAAGAGCTACCACTGGATGGGCCTCG } \\
\text { TGCACATCCCTACCAATGGCTCTTGGCAGTGGGAG } \\
\text { GACGGCAGCATTCTGAGCCCTAACCTGCTGACCATC } \\
\text { ATCGAGATGCAGAAGGGCGACTGCGCCTGTACGC } \\
\text { CAGCAGCTTTAAGGGCTACATCGAGAACTGCAGCA } \\
\text { CCCCTAACACCTACATCTGTATGCAGCGGACCGTGC } \\
\text { CCAGCCCCGCCGACCTGAGCCCCGGCGCCAGCAGC } \\
\text { GTGACCCCCCCCGCCCCCGCCAGGGAGCCCGGCCA } \\
\text { CAGCCCCCAGATCATCAGCTTCTTCCTGGCCCTGAC } \\
\text { CAGCACCGCCCTGCTGTTCCTGCTGTTCTTCCTGACC } \\
\text { CTGAGGTTCAGCGTGGTGAAGCGGGGCAGAA } \\
\text { AGAAGCTGCTGTACATCTTCAAGCAGCCCTTCATGC } \\
\text { GGCCCGTGCAGACCACACAAGAGGAAGATGGCTG } \\
\text { CTCCTGCAGATTCCCCGAGGAAGAAGAAGGCGGCT } \\
\text { GCGAGCTGTGAGGATCC }\end{array}$ & $\begin{array}{l}\text { MALLLLLPLLWAGALA } \\
\text { MESYCGPCPKNWICYK } \\
\text { NNCYQFFDESKNWYE } \\
\text { SQASCMSQNASLLKV } \\
\text { YSKEDQDLLKLVKSYH } \\
\text { WMGLVHIPTNGSWQ } \\
\text { WEDGSILSPNLLTIIEM } \\
\text { QKGDCALYASSFKGYIE } \\
\text { NCSTPNTYICMQRTVP } \\
\text { SPADLSPGASSVTPPA } \\
\text { PAREPGHSPQIISFFLAL } \\
\text { TSTALLFLLFFLTLRFSV } \\
\text { VKRGRKKLLYIFKQPFM } \\
\text { RPVQTTQEEDGCSCRF } \\
\text { PEEEEGGCEL- }\end{array}$ \\
\hline $\begin{array}{c}\text { P2A_CD33_NKG2D_linker_ } \\
\text { ICOStm + cyto }\end{array}$ & $\begin{array}{l}\text { CTCGAGGGCAGCGGCGCCACAAATTTCAGCCTGCT } \\
\text { GAAACAGGCCGGCGACGTCGAAGAAAATCCTGGA } \\
\text { CCAATGGCCCTGCTGCTGCTGCTGCCACTGCTGTGG } \\
\text { GCCGGGGCCCTGGCTATGGAGAGCTACTGCGGCCC } \\
\text { CTGCCCCAAGAACTGGATCTGCTACAAGAACAACT } \\
\text { GCTACCAGTTCTTCGATGAGAGCAAGAACTGGTAC } \\
\text { GAGAGCCAGGCCAGCTGCATGAGCCAGAACGCAA } \\
\text { GCCTGCTGAAGGTGTACAGCAAGGAGGACCAGGAT } \\
\text { CTGCTGAAGCTGGTGAAGAGCTACCACTGGATGGG } \\
\text { GCTGGTACATATTCCTACTAACGGCTCATGGCAGTG } \\
\text { GGAGGATGGAAGCATTCTGAGCCCTAACTTGTTGAC } \\
\text { TATTATCGAGATGCAGAAGGGCGATTGCGCCCTGTA }\end{array}$ & $\begin{array}{l}\text { MALLLLLPLLWAGALA } \\
\text { MESYCGPCPKNWICYK } \\
\text { NNCYQFFDESKNWYE } \\
\text { SQASCMSQNASLLKV } \\
\text { YSKEDQDLLKLVKSYH } \\
\text { WMGLVHIPTNGSWQ } \\
\text { WEDGSILSPNLLTIIEM } \\
\text { QKGDCALYASSFKGYIE } \\
\text { NCSTPNTYICMQRTVS } \\
\text { QLCCQLKFWLPIGCAA } \\
\text { FVVVILGCILICWLTKK } \\
\text { KYSSSVHDPNGEYMF }\end{array}$ \\
\hline
\end{tabular}




\begin{tabular}{|c|c|c|}
\hline & $\begin{array}{l}\text { CGCCAGCAGCTTCAAGGGCTACATCGAGAACTGCA } \\
\text { GCACTCCCAACACATACATCTGCATGCAGCGGACA } \\
\text { GTGAGTCAGCTGTGCTGCCAGCTGAAGTTTTGGCTG } \\
\text { CCAATTGGATGCGCTGCCTTTGTGGTGGTGTGCATT } \\
\text { CTGGGATGCATTCTGATTTGTTGGCTTACAAAGAAA } \\
\text { AAGTACAGCTCTAGCGTGCATGATCCTAACGGGGA } \\
\text { GTACATGTTTATGAGGGCCGTGAACACAGCCAAGA } \\
\text { AGAGCAGACTGACAGATGTGACACTGTGAAAGCTT }\end{array}$ & $\begin{array}{l}\text { MRAVNTAKKSRLTDVT } \\
\text { L- }\end{array}$ \\
\hline $\begin{array}{l}\text { P2A_CD33_NKG2D_linker_ } \\
\text { CD28tm + cyto }\end{array}$ & $\begin{array}{l}\text { CTCGAGGGCAGCGGCGCCACAAATTTCAGCCTGCT } \\
\text { GAAACAGGCCGGCGACGTCGAAGAAAATCCTGGA } \\
\text { CCAATGGCCCTGCTGCTGCTGCTGCCCCTGCTGTGG } \\
\text { GCCGGCGCCCTGGCTATGGAGAGCTACTGCGGCCC } \\
\text { CTGCCCCAAGAACTGGATCTGCTACAAGAACAACT } \\
\text { GCTACCAGTTCTTCGATGAGAGCAAGAACTGGTAC } \\
\text { GAGTCCCAGGCCAGCTGCATGTCCCAGAACGCCAG } \\
\text { CCTACTGAAGGTGTACAGCAAGGAGGATCAGGACC } \\
\text { TGCTCAAGCTGGTGAAGAGCTACCATTGGATGGGC } \\
\text { CTGGTGCACATCCCCACCAACGGCAGCTGGCAGTG } \\
\text { GGAGGACGGGAGCATCCTGTCCCCCAACCTGCTGA } \\
\text { CCATCATCGAGATGCAGAAGGGGGATTGCGCCTTG } \\
\text { TACGCCAGCTCCTTCAAGGGATACATCGAGAACTGC } \\
\text { AGCACACCCAACACCTACATCTGCATGCAGCGGAC } \\
\text { CGTGGGGAAGCACCTGTGCCCCAGCCCCCTCTTCC } \\
\text { CCGGCCCCAGCAAGCCCTTCTGGGTGCTGGTGGTG } \\
\text { GTGGGGGGGGTGCTGGCCTGCTACAGCCTGCTGGT } \\
\text { CACAGTGGCCTTCATCATCTTCTGGGTCAGAAGCAA } \\
\text { GAGGAGCCGGCTGCTCCACAGCGACTACATGAACA } \\
\text { TGACACCCAGAAGGCCCGGCCCCACACGGAAGCA } \\
\text { CTACCAGCCCTACGCCCCCCCACGGGACTTTGCCGC } \\
\text { CTACAGGTCCTGAAAGCTT }\end{array}$ & $\begin{array}{l}\text { MALLLLLPLLWAGALA } \\
\text { MESYCGPCPKNWICYK } \\
\text { NNCYQFFDESKNWYE } \\
\text { SQASCMSQNASLLKV } \\
\text { YSKEDQDLLKLVKSYH } \\
\text { WMGLVHIPTNGSWQ } \\
\text { WEDGSILSPNLLTIIEM } \\
\text { QKGDCALYASSFKGYIE } \\
\text { NCSTPNTYICMQRTVG } \\
\text { KHLCPSPLFPGPSKPF } \\
\text { WVLVVVGGVLACYSLL } \\
\text { VTVAFIIFWVRSKRSRL } \\
\text { LHSDYMNMTPRRPGP } \\
\text { TRKHYQPYAPPRDFAA } \\
\text { YRS- }\end{array}$ \\
\hline $\begin{array}{c}\text { P2A_CD33_NKG2D_linker_ } \\
\text { 4-1BB tm + cyto }\end{array}$ & $\begin{array}{l}\text { CTCGAGGGCAGCGGCGCCACAAATTTCAGCCTGCT } \\
\text { GAAACAGGCCGGCGACGTCGAAGAAATCCTGGA } \\
\text { CCAATGGCCCTGCTGCTGCTGCTGCCCCTGCTGTGG } \\
\text { GCCGGGGCCCTGGCTATGGAGAGCTACTGCGGCCC } \\
\text { CTGCCCCAAGAACTGGATCTGCTACAAGAACAACT } \\
\text { GCTACCAGTTCTTCGATGAGAGCAAGAACTGGTAC } \\
\text { GAGAGCCAGGCCAGCTGCATGAGCCAGAACGCCA } \\
\text { GCCTGCTGAAGGTGTACTCCAAGGAGGATCAGGAC } \\
\text { CTGCTGAAGCTGGTGAAGAGCTACCACTGGATGGG } \\
\text { GCTGGTGCACATCCCCACAAACGGGAGCTGGCAGT } \\
\text { GGGAGGATGGCAGCATCCTGAGCCCCAACCTGCTG } \\
\text { ACCATCATCGAGATGCAGAAGGCGACTGCGCCCT } \\
\text { GTACGCCAGCAGCTTCAAGGGGTACATTGAGAACT } \\
\text { GCAGCACACCCAACACCTACATCTGCATGCAGAGA } \\
\text { ACAGTTCCTAGTCCTGCAGACTTGTCCCCAGGAGCT } \\
\text { TCTAGCGTGACCCCTCCAGCTCCAGCTAGAGAACCT } \\
\text { GGACATAGCCCACAGATAATTAGTTTCTTTTGGCC } \\
\text { CTGACCTCCACAGCCCTGCTTTTCCTGCTGTTTTTCTT } \\
\text { GACTTTGAGATTCTCCGTAGTGAAGCGGGGGAGGA } \\
\text { AGAAACTCCTGTACATCTTTAAGCAGCCCTTCATGA } \\
\text { GGCCAGTCCAGACCACCCAGGAGGAGGACGGCTG } \\
\text { TAGCTGTAGGTTCCCAGAGGAGGAGGAAGGAGGCT } \\
\text { GTGAGCTGTGAAAGCTT }\end{array}$ & $\begin{array}{l}\text { MALLLLLPLLWAGALA } \\
\text { MESYCGPCPKNWICYK } \\
\text { NNCYQFFDESKNWYE } \\
\text { SQASCMSQNASLLKV } \\
\text { YSKEDQDLLKLVKSYH } \\
\text { WMGLVHIPTNGSWQ } \\
\text { WEDGSILSPNLLTIIEM } \\
\text { QKGDCALYASSFKGYE } \\
\text { NCSTPNTYICMQRTVP } \\
\text { SPADLSPGASSVTPPA } \\
\text { PAREPGHSPQIISFFLAL } \\
\text { TSTALLFLLFFLTLRFSV } \\
\text { VKRGRKKLLYIFKQPFM } \\
\text { RPVQTTQEEDGCSCRF } \\
\text { PEEEEGGCEL- }\end{array}$ \\
\hline
\end{tabular}




\begin{tabular}{|c|c|c|}
\hline $\begin{array}{c}\text { P2A_NKG2D_CD28tm + linker_ } \\
\text { ICOScyto }\end{array}$ & $\begin{array}{l}\text { CTCGAGGGCAGCGGCGCCACAAATTTCAGCCTGCT } \\
\text { GAAACAGGCCGGCGACGTCGAAGAAAATCCTGGA } \\
\text { CCAATGGCCCTGCTGCTGCTGCTGCCCCTGCTGTGG } \\
\text { GCCGGCGCCCTGGCTATGGAGAGCTACTGCGGCCC } \\
\text { CTGCCCCAAGAACTGGATCTGCTACAAGAACAACT } \\
\text { GCTACCAGTTCTTCGATGAGAGCAAGAACTGGTAC } \\
\text { GAGTCCCAGGCCAGCTGCATGTCCCAGAACGCCAG } \\
\text { CCTACTGAAGGTGTACAGCAAGGAGGATCAGGACC } \\
\text { TGCTCAAGCTGGTGAAGAGCTACCATTGGATGGGC } \\
\text { CTGGTGCACATCCCCACCAACGGCAGCTGGCAGTG } \\
\text { GGAGGACGGGAGCATCCTGTCCCCCAACCTGCTGA } \\
\text { CCATCATCGAGATGCAGAAGGGGGTTGCGCCTTG } \\
\text { TACGCCAGCTCCTTCAAGGGATACATCGAGAACTGC } \\
\text { AGCACACCCAACACCTACATCTGCATGCAGCGGAC } \\
\text { CGTGGGGAAGCACCTGTGCCCCAGCCCCCTCTTCC } \\
\text { CCGGCCCCAGCAAGCCCTTCTGGGTGCTGGTGGTG } \\
\text { GTGGGGGGGGTGCTGGCCTGCTACAGCCTGCTGGT } \\
\text { CACAGTGGCCTTCATCATCTTCTGGGTCTGTTGGCTT } \\
\text { ACAAAGAAAAAGTACAGCTCTAGCGTGCATGATCC } \\
\text { TAACGGGGAGTACATGTTTATGAGGGCCGTGAACA } \\
\text { CAGCCAAGAAGAGCAGACTGACAGATGTGACACTG } \\
\text { TGAAAGCTT }\end{array}$ & $\begin{array}{l}\text { MALLLLLPLLWAGALA } \\
\text { MESYCGPCPKNWICYK } \\
\text { NNCYQFFDESKNWYE } \\
\text { SQASCMSQNASLLKV } \\
\text { YSKEDQDLLKLVKSYH } \\
\text { WMGLVHIPTNGSWQ } \\
\text { WEDGSILSPNLLTIIEM } \\
\text { QKGDCALYASSFKGYIE } \\
\text { NCSTPNTYICMQRTVG } \\
\text { KHLCPSPLFPGPSKPF } \\
\text { WVLVVVGGVLACYSLL } \\
\text { VTVAFIIFWVCWLTKKK } \\
\text { YSSSVHDPNGEYMFM } \\
\text { RAVNTAKKSRLTDVTL- }\end{array}$ \\
\hline $\begin{array}{c}\text { P2A_NKG2D_CD28tm + linker_ } \\
\text { 4-1BBcyto }\end{array}$ & $\begin{array}{l}\text { CTCGAGGGCAGCGGCGCCACAAATTTCAGCCTGCT } \\
\text { GAAACAGGCCGGCGACGTCGAAGAAAATCCTGGA } \\
\text { CCAATGGCCCTGCTGCTGCTGCTGCCCCTGCTGTGG } \\
\text { GCCGGCGCCCTGGCTATGGAGAGCTACTGCGGCCC } \\
\text { CTGCCCCAAGAACTGGATCTGCTACAAGAACAACT } \\
\text { GCTACCAGTTCTTCGATGAGAGCAAGAACTGGTAC } \\
\text { GAGTCCCAGGCCAGCTGCATGTCCCAGAACGCCAG } \\
\text { CCTACTGAAGGTGTACAGCAAGGAGGATCAGGACC } \\
\text { TGCTCAAGCTGGTGAAGAGCTACCATTGGATGGGC } \\
\text { CTGGTGCACATCCCCACCAACGGCAGCTGGCAGTG } \\
\text { GGAGGACGGGAGCATCCTGTCCCCCAACCTGCTGA } \\
\text { CCATCATCGAGATGCAGAAGGGGATTGCGCCTTG } \\
\text { TACGCCAGCTCCTTCAAGGGATACATCGAGAACTGC } \\
\text { AGCACACCCAACACCTACATCTGCATGCAGCGGAC } \\
\text { CGTGGGGAAGCACCTGTGCCCCAGCCCCCTCTTCC } \\
\text { CCGGCCCCAGCAAGCCCTTCTGGGTGCTGGTGGTG } \\
\text { GTGGGGGGGGTGCTGGCCTGCTACAGCCTGCTGGT } \\
\text { CACAGTGGCCTTCATCATCTTCTGGGTCAAGCGGGG } \\
\text { GAGGAAGAAACTCCTGTACATCTTTAAGCAGCCCTT } \\
\text { CATGAGGCCAGTCCAGACCACCCAGGAGGAGGAC } \\
\text { GGCTGTAGCTGTAGGTTCCCAGAGGAGGAGGAAGG } \\
\text { AGGCTGTGAGCTGTGAAAGCTT }\end{array}$ & $\begin{array}{l}\text { MALLLLLPLLWAGALA } \\
\text { MESYCGPCPKNWICYK } \\
\text { NNCYQFFDESKNWYE } \\
\text { SQASCMSQNASLLKV } \\
\text { YSKEDQDLLKLVKSYH } \\
\text { WMGLVHIPTNGSWQ } \\
\text { WEDGSILSPNLLTIIEM } \\
\text { QKGDCALYASSFKGYIE } \\
\text { NCSTPNTYICMQRTVG } \\
\text { KHLCPSPLFPGPSKPF } \\
\text { WVLVVVGGLACYSLL } \\
\text { VTVAFIIFWVKRGRKKL } \\
\text { LYIFKQPFMRPVQTTQ } \\
\text { EEDGCSCRFPEEEEGG } \\
\text { CEL- }\end{array}$ \\
\hline Cl5_V $\mathrm{V}_{\delta_{-}} C_{\alpha_{-}} \mathrm{Cys}$ & $\begin{array}{l}\text { ATGGAGCGGATCAGCAGCCTGATCCACCTGAGCCT } \\
\text { GTTCTGGGCCGGAGTGATGAGCGCCATCGAGCTGG } \\
\text { TGCCCGAGCACCAGACCGTGCCCGTGAGCATCGGC } \\
\text { GTGCCCGCCACCCTGCGGTGCAGCATGAAGGGCGA } \\
\text { GGCCATCGGCAACTACTACATCAACTGGTACAGAA } \\
\text { AGACCCAGGGCAACACCATGACCTTCATCTACCGG } \\
\text { GAGAAGGACATCTACGGCCCTGGCTTCAAGGACAA } \\
\text { CTTCCAGGGCGACATCGACATCGCCAAGAACCTGG } \\
\text { CCGTGCTGAAGATCCTGGCCCCCAGCGAGAGGGAC }\end{array}$ & $\begin{array}{l}\text { MERISSLIHLSLFWAGV } \\
\text { MSAIELVPEHQTVPVSI } \\
\text { GVPATLRCSMKGEAIG } \\
\text { NYYINWYRKTQGNTM } \\
\text { TFIYREKDIYGPGFKDN } \\
\text { FQGDIDIAKNLAVLKIL } \\
\text { APSERDEGSYYCACDA } \\
\text { LKRTDTDKLIFGKGTRV } \\
\text { TVEPNIQNPDPAVYQL }\end{array}$ \\
\hline
\end{tabular}




\begin{tabular}{|c|c|c|}
\hline & $\begin{array}{l}\text { GAGGGCAGCTACTACTGCGCCTGCGACGCCCTGAA } \\
\text { GAGAACCGACACCGACAAGCTGATCTTCGGCAAGG } \\
\text { GCACCCGGGTGACCGTGGAGCCCAACATCCAGAAC } \\
\text { CCCGACCCCGCGGTGTACCAGCTGCGGGACAGCAA } \\
\text { GAGCAGCGACAAGAGCGTGTGCCTGTTCACCGACT } \\
\text { TCGACAGCCAGACCAACGTGAGCCAGAGCAAGGA } \\
\text { CTCCGACGTGTACATCACCGACAAGTGCGTGCTGG } \\
\text { ACATGCGGAGCATGGACTTCAAGAGCAACTCCGCC } \\
\text { GTGGCCTGGTCCAACAAGAGCGACTTCGCCTGCGC } \\
\text { CAACGCCTTCAACAACAGCATCATCCCCGAGGACA } \\
\text { CCTTTTTCCCCAGCCCCGAGAGCAGCTGCGACGTGA } \\
\text { AACTGGTGGAGAAGAGCTTCGAGACCGACACCAAC } \\
\text { CTGAACTTCCAGAACCTGAGCGTGATCGGCTTCAGA } \\
\text { ATCCTGCTGCTGAAGGTGGCCGGCTTCAACCTGCTG } \\
\text { ATGACCCTGCGGCTGTGGAGCAGCTGAG }\end{array}$ & $\begin{array}{l}\text { RDSKSSDKSVCLFTDF } \\
\text { DSQTNVSQSKDSDVYI } \\
\text { TDKCVLDMRSMDFKS } \\
\text { NSAVAWSNKSDFACA } \\
\text { NAFNNSIIPEDTFFPSP } \\
\text { ESSCDVKLVEKSFETDT } \\
\text { NLNFQNLSVIGFRILLL } \\
\text { KVAGFNLLMTLRLWSS } \\
-\end{array}$ \\
\hline Cl5_V $V_{\delta} C_{\delta} L_{\alpha} \operatorname{Tm}_{\alpha}$ & $\begin{array}{l}\text { ATGGAGCGGATCAGCAGCCTGATCCACCTGAGCCT } \\
\text { GTTCTGGGCCGGAGTGATGAGCGCCATCGAGCTGG } \\
\text { TGCCCGAGCACCAGACCGTGCCCGTGAGCATCGGC } \\
\text { GTGCCCGCCACCCTGCGGTGCAGCATGAAGGGCGA } \\
\text { GGCCATCGGCAACTACTACATCAACTGGTACAGAA } \\
\text { AGACCCAGGGCAACACCATGACCTTCATCTACCGG } \\
\text { GAGAAGGACATCTACGGCCCTGGCTTCAAGGACAA } \\
\text { CTTCCAGGGCGACATCGACATCGCCAAGAACCTGG } \\
\text { CCGTGCTGAAGATCCTGGCCCCCAGCGAGAGGGAC } \\
\text { GAGGGCAGCTACTACTGCGCCTGCGACGCCCTGAA } \\
\text { GAGAACCGACACCGACAAGCTGATCTTCGGCAAGG } \\
\text { GCACCCGGGTGACCGTGGAGCCCAGAAGCCAGCC } \\
\text { CCACACCAAGCCCAGCGTGTTCGTGATGAAGAACG } \\
\text { GCACCAACGTGGCCTGCCTGGTGAAAGAGTTCTAC } \\
\text { CCCAAGGACATCCGGATCAACCTGGTGTCCAGCAA } \\
\text { GAAGATCACCGAGTTCGACCCCGCCATCGTGATCA } \\
\text { GCCCCAGCGGCAAGTACAACGCCGTGAAGCTGGGC } \\
\text { AAGTACGAGGACAGCAACAGCGTGACCTGCAGCGT } \\
\text { GCAGCACGACAACAAGACCGTGCACAGCACCGACT } \\
\text { TCGAGGTGAAAACCGACTCCACCGACCACGTGAAG } \\
\text { CCCAAAGAGACCGAGAACACCAAGCAGCCCAGCA } \\
\text { AGAGCTGCGACGTGAAACTGGTGGAGAAGAGCTTC } \\
\text { GAGACCGACACCAACCTGAACTTCCAGAACCTGAG } \\
\text { CGTGATCGGCTTCAGAATCCTGCTGCTGAAGGTGGC } \\
\text { CGGCTTCAACCTGCTGATGACCCTGCGGCTGTGGA } \\
\text { GCAGCTGAG }\end{array}$ & $\begin{array}{l}\text { MERISSLIHLSLFWAGV } \\
\text { MSAIELVPEHQTVPVSI } \\
\text { GVPATLRCSMKGEAIG } \\
\text { NYYINWYRKTQGNTM } \\
\text { TFIYREKDIYGPGFKDN } \\
\text { FQGDIDIAKNLAVLKIL } \\
\text { APSERDEGSYYCACDA } \\
\text { LKRTDTDKLIFGKGTRV } \\
\text { TVEPRSQPHTKPSVFV } \\
\text { MKNGTNVACLVKEFY } \\
\text { PKDIRINLVSSKKITEFD } \\
\text { PAIVISPSGKYNAVKLG } \\
\text { KYEDSNSVTCSVQHD } \\
\text { NKTVHSTDFEVKTDST } \\
\text { DHVKPKETENTKQPSK } \\
\text { SCDVKLVEKSFETDTNL } \\
\text { NFQNLSVIGFRILLLKV } \\
\text { AGFNLLMTLRLWSS- }\end{array}$ \\
\hline Cl5_V $\mathrm{V}_{\delta} \mathrm{C}_{\delta} \mathrm{Li}_{\delta_{-}} \mathrm{Tm}_{\alpha}$ & $\begin{array}{l}\text { ATGGAGCGGATCAGCAGCCTGATCCACCTGAGCCT } \\
\text { GTTCTGGGCCGGAGTGATGAGCGCCATCGAGCTGG } \\
\text { TGCCCGAGCACCAGACCGTGCCCGTGAGCATCGGC } \\
\text { GTGCCCGCCACCCTGCGGTGCAGCATGAAGGGCGA } \\
\text { GGCCATCGGCAACTACTACATCAACTGGTACAGAA } \\
\text { AGACCCAGGGCAACACCATGACCTTCATCTACCGG } \\
\text { GAGAAGGACATCTACGGCCCTGGCTTCAAGGACAA } \\
\text { CTTCCAGGGCGACATCGACATCGCCAAGAACCTGG } \\
\text { CCGTGCTGAAGATCCTGGCCCCCAGCGAGAGGGAC } \\
\text { GAGGGCAGCTACTACTGCGCCTGCGACGCCCTGAA } \\
\text { GAGAACCGACACCGACAAGCTGATCTTCGGCAAGG } \\
\text { GCACCCGGGTGACCGTGGAGCCCAGAAGCCAGCC }\end{array}$ & $\begin{array}{l}\text { MERISSLIHLSLFWAGV } \\
\text { MSAIELVPEHQTVPVSI } \\
\text { GVPATLRCSMKGEAIG } \\
\text { NYYINWYRKTQGNTM } \\
\text { TFIYREKDIYGPGFKDN } \\
\text { FQGDIDIAKNLAVLKIL } \\
\text { APSERDEGSYYCACDA } \\
\text { LKRTDTDKLIFGKGTRV } \\
\text { TVEPRSQPHTKPSVFV } \\
\text { MKNGTNVACLVKEFY } \\
\text { PKDIRINLVSSKITEFD } \\
\text { PAIVISPSGKYNAVKLG }\end{array}$ \\
\hline
\end{tabular}




\begin{tabular}{|c|c|c|}
\hline & $\begin{array}{l}\text { CCACACCAAGCCCAGCGTGTTCGTGATGAAGAACG } \\
\text { GCACCAACGTGGCCTGCCTGGTGAAAGAGTTCTAC } \\
\text { CCCAAGGACATCCGGATCAACCTGGTGTCCAGCAA } \\
\text { GAAGATCACCGAGTTCGACCCCGCCATCGTGATCA } \\
\text { GCCCCAGCGGCAAGTACAACGCCGTGAAGCTGGGC } \\
\text { AAGTACGAGGACAGCAACAGCGTGACCTGCAGCGT } \\
\text { GCAGCACGACAACAAGACCGTGCACAGCACCGACT } \\
\text { TCGAGGTGAAAACCGACTCCACCGACCACGTGAAG } \\
\text { CCCAAAGAGACCGAGAACACCAAGCAGCCCAGCA } \\
\text { AGAGCTGCCACAAGCCCAAGGCCATCGTGCACACC } \\
\text { GAGAAGCTGAACTTCCAGAACCTGAGCGTGATCGG } \\
\text { CTTCAGAATCCTGCTGCTGAAGGTGGCCGGCTTCAA } \\
\text { CCTGCTGATGACCCTGCGGCTGTGGAGCAGCTGAG }\end{array}$ & $\begin{array}{l}\text { KYEDSNSVTCSVQHD } \\
\text { NKTVHSTDFEVKTDST } \\
\text { DHVKPKETENTKQPSK } \\
\text { SCHKPKAIVHTEKLNF } \\
\text { QNLSVIGFRILLLKVAG } \\
\text { FNLLMTLRLWSS- }\end{array}$ \\
\hline $\mathrm{Cl} 5 \_\mathrm{V}_{\gamma_{-}} \mathrm{C}_{\boldsymbol{\beta}}$ & $\begin{array}{l}\text { ATGGTGTCCCTGCTGCACGCCAGCACCCTGGCCGT } \\
\text { GCTGGGCGCCCTGTGCGTGTATGGCGCCGGACACC } \\
\text { TGGAACAGCCCCAGATCAGCAGCACCAAGACCCTG } \\
\text { AGCAAGACCGCCAGGCTGGAATGCGTGGTGTCCGG } \\
\text { CATCACCATCAGCGCCACCTCCGTGTACTGGTACAG } \\
\text { AGAGAGACCCGGCGAGGTCATCCAGTTCCTGGTGT } \\
\text { CCATCAGCTACGACGGCACCGTGCGGAAAGAGAGC } \\
\text { GGCATCCCCAGCGGCAAGTTCGAGGTGACAGAAT } \\
\text { CCCCGAGACCAGCACCTCCACCCTGACCATCCACA } \\
\text { ACGTGGAGAAGCAGGACATCGCCACCTACTACTGC } \\
\text { GCCCTGTGGGAGATCCAGGAACTGGGCAAGAAAAT } \\
\text { CAAGGTGTTCGGCCCTGGCACCAAGCTGATCATCA } \\
\text { CCGAAGATCTGAAGAACGTGTTCCCCCCCGAGTG } \\
\text { GCCGTGTTCGAGCCCAGCGAGGCCGAGATCAGCCA } \\
\text { CACCCAGAAAGCCACCCTGGTCTGCCTGGCCACCG } \\
\text { GCTTCTACCCCGACCACGTGGAGCTGTCTTGGTGGG } \\
\text { TGAACGGCAAAGAGGTGCACAGCGGCGTCTGCACC } \\
\text { GACCCCCAGCCCCTGAAAGAGCAGCCCGCCCTGAA } \\
\text { CGACAGCCGGTACTGCCTGAGCAGCCGGCTGAGAG } \\
\text { TGAGCGCCACCTTCTGGCAGAACCCCCGGAACCAC } \\
\text { TTCCGGTGCCAGGTGCAGTTCTACGGCCTGAGCGA } \\
\text { GAACGACGAGTGGACCCAGGACAGAGCCAAGCCC } \\
\text { GTGACCCAGATCGTGAGCGCCGAGGCCTGGGGCA } \\
\text { GAGCCGACTGCGGCTTCACCAGCGAGAGCTACCAG } \\
\text { CAGGGCGTGCTGTCCGCCACCATCCTGTACGAGAT } \\
\text { CCTGCTGGGCAAGGCCACACTGTACGCCGTGCTGG } \\
\text { TGTCCGCCCTGGTGCTGATGGCTATGGTGAAGCGG } \\
\text { AAGGACAGCCGGGGCTGAG }\end{array}$ & $\begin{array}{l}\text { MVSLLHASTLAVLGAL } \\
\text { CVYGAGHLEQPQISST } \\
\text { KTLSKTARLECVVSGITI } \\
\text { SATSVYWYRERPGEVI } \\
\text { QFLVSISYDGTVRKESG } \\
\text { IPSGKFEVDRIPETSTST } \\
\text { LTIHNVEKQDIATYYCA } \\
\text { LWEIQELGKKIKVFGPG } \\
\text { TKLIITEDLKNVFPPEVA } \\
\text { VFEPSEAEISHTQKATL } \\
\text { VCLATGFYPDHVELSW } \\
\text { WVNGKEVHSGVCTDP } \\
\text { QPLKEQPALNDSRYCL } \\
\text { SSRLRVSATFWQNPR } \\
\text { NHFRCQVQFYGLSEN } \\
\text { DEWTQDRAKPVTQIVS } \\
\text { AEAWGRADCGFTSESY } \\
\text { QQGVLSATILYEILLGK } \\
\text { ATLYAVLVSALVLMAM } \\
\text { VKRKDSRG- }\end{array}$ \\
\hline Cl5_ $\mathrm{V}_{\gamma} \mathrm{C}_{\gamma_{-}} \mathrm{Li}_{\beta} \mathrm{Tm}_{\beta}$ & $\begin{array}{l}\text { ATGGTGTCCCTGCTGCACGCCAGCACCCTGGCCGT } \\
\text { GCTGGGCGCCCTGTGCGTGTATGGCGCCGGACACC } \\
\text { TGGAACAGCCCCAGATCAGCAGCACCAAGACCCTG } \\
\text { AGCAAGACCGCCAGGCTGGAATGCGTGGTGTCCGG } \\
\text { CATCACCATCAGCGCCACCTCCGTGTACTGGTACAG } \\
\text { AGAGAGACCCGGCGAGGTCATCCAGTTCCTGGTGT } \\
\text { CCATCAGCTACGACGGCACCGTGCGGAAAGAGAGC } \\
\text { GGCATCCCCAGCGGCAAGTTCGAGGTGGACAGAAT } \\
\text { CCCCGAGACCAGCACCTCCACCCTGACCATCCACA } \\
\text { ACGTGGAGAAGCAGGACATCGCCACCTACTACTGC } \\
\text { GCCCTGTGGGAGATCCAGGAACTGGGCAAGAAAAT } \\
\text { CAAGGTGTTCGGCCCTGGCACCAAGCTGATCATCA }\end{array}$ & $\begin{array}{l}\text { MVSLLHASTLAVLGAL } \\
\text { CVYGAGHLEQPQISST } \\
\text { KTLSKTARLECVVSGITI } \\
\text { SATSVYWYRERPGEVI } \\
\text { QFLVSISYDGTVRKESG } \\
\text { IPSGKFEVDRIPETSTST } \\
\text { LTIHNVEKQDIATYYCA } \\
\text { LWEIQELGKKIKVFGPG } \\
\text { TKLIITDKQLDADVSPK } \\
\text { PTIFLPSIAETKLQKAGT } \\
\text { YLCLLEKFFPDVIKIHWE } \\
\text { EKKSNTILGSQEGNTM }\end{array}$ \\
\hline
\end{tabular}




\begin{tabular}{|c|c|c|}
\hline & $\begin{array}{l}\text { CCGACAAGCAGCTGGACGCCGACGTGAGCCCCAA } \\
\text { GCCTACCATCTTCCTGCCCAGCATCGCCGAGACCAA } \\
\text { GCTGCAGAAGGCCGGCACCTACCTGTGCCTGCTGG } \\
\text { AAAAGTTCTTCCCCGACGTGATCAAGATCCACTGGG } \\
\text { AGGAAAAGAAGAGCAACACCATCCTGGGCAGCCA } \\
\text { GGAAGGCAATACCATGAAAACCAACGACACCTACA } \\
\text { TGAAGTTCAGCTGGCTGACCGTGCCCGAGAAGAGC } \\
\text { CTGGACAAAGAGCACAGATGCATCGTCCGGCACGA } \\
\text { GAACAACAAGAACGGCGTGGACCAGGAAATCATCT } \\
\text { TCCCCCCCATCAAGACCGATGTGATCACAATGGACC } \\
\text { CCAAGGACAACTGCGGCTTCACCAGCGAGAGCTAC } \\
\text { CAGCAGGGCGTGCTGTCCGCCACCATCCTGTACGA } \\
\text { GATCCTGCTGGGCAAGGCCACACTGTACGCCGTGC } \\
\text { TGGTGTCCGCCCTGGTGCTGATGGCTATGGTGAAGC } \\
\text { GGAAGGACAGCCGGGGCTGAG }\end{array}$ & $\begin{array}{l}\text { KTNDTYMKFSWLTVPE } \\
\text { KSLDKEHRCIVRHENN } \\
\text { KNGVDQEIIFPPIKTDVI } \\
\text { TMDPKDNCGFTSESY } \\
\text { QQGVLSATILYEILLGK } \\
\text { ATLYAVLVSALVLMAM } \\
\text { VKRKDSRG- }\end{array}$ \\
\hline Cl5_ $V_{\gamma} C_{\gamma} L_{Y_{-}} T m_{\beta}$ & $\begin{array}{l}\text { ATGGTGTCCCTGCTGCACGCCAGCACCCTGGCCGT } \\
\text { GCTGGGCGCCCTGTGCGTGTATGGCGCCGGACACC } \\
\text { TGGAACAGCCCCAGATCAGCAGCACCAAGACCCTG } \\
\text { AGCAAGACCGCCAGGCTGGAATGCGTGGTGTCCGG } \\
\text { CATCACCATCAGCGCCACCTCCGTGTACTGGTACAG } \\
\text { AGAGAGACCCGGCGAGGTCATCCAGTTCCTGGTGT } \\
\text { CCATCAGCTACGACGGCACCGTGCGGAAAGAGAGC } \\
\text { GGCATCCCCAGCGGCAAGTTCGAGGTGGACAGAAT } \\
\text { CCCCGAGACCAGCACCTCCACCCTGACCATCCACA } \\
\text { ACGTGGAGAAGCAGGACATCGCCACCTACTACTGC } \\
\text { GCCCTGTGGGAGATCCAGGAACTGGGCAAGAAAAT } \\
\text { CAAGGTGTTCGGCCCTGGCACCAAGCTGATCATCA } \\
\text { CCGACAAGCAGCTGGACGCCACGTGAGCCCCAA } \\
\text { GCCTACCATCTTCCTGCCCAGCATCGCCGAGACCAA } \\
\text { GCTGCAGAAGGCCGGCACCTACCTGTGCCTGCTGG } \\
\text { AAAAGTTCTTCCCCGACGTGATCAAGATCCACTGGG } \\
\text { AGGAAAAGAAGAGCAACACCATCCTGGGCAGCCA } \\
\text { GGAAGGCAATACCATGAAAACCAACGACACCTACA } \\
\text { TGAAGTTCAGCTGGCTGACCGTGCCCGAGAAGAGC } \\
\text { CTGGACAAAGAGCACAGATGCATCGTCCGGCACGA } \\
\text { GAACAACAAGAACGGCGTGGACCAGGAAATCATCT } \\
\text { TCCCCCCATCAAGACCGATGTGATCACAATGGACC } \\
\text { CCAAGGACAACTGCAGCAAGGACGCCAACGATACC } \\
\text { CTGCTGCTGCAGCTGACCAACCTGTCCGCCACCATC } \\
\text { CTGTACGAGATCCTGCTGGGCAAGGCCACACTGTA } \\
\text { CGCCGTGCTGGTGTCCGCCCTG } \\
\text { GTGCTGATGGCTATGGTGAAGCGGAAGGACAGCCG } \\
\text { GGGCTGAG }\end{array}$ & $\begin{array}{l}\text { MVSLLHASTLAVLGAL } \\
\text { CVYGAGHLEQPQISST } \\
\text { KTLSKTARLECVVSGITI } \\
\text { SATSVYWYRERPGEVI } \\
\text { QFLVSISYDGTVRKESG } \\
\text { IPSGKFEVDRIPETSTST } \\
\text { LTIHNVEKQDIATYYCA } \\
\text { LWEIQELGKKIKVFGPG } \\
\text { TKLIITDKQLDADVSPK } \\
\text { PTIFLPSIAETKLQKAGT } \\
\text { YLCLLEKFFPDVIKIHWE } \\
\text { EKKSNTILGSQEGNTM } \\
\text { KTNDTYMKFSWLTVPE } \\
\text { KSLDKEHRCIVRHENN } \\
\text { KNGVVDEIIFPPIKTDVI } \\
\text { TMDPKDNCSKDANDT } \\
\text { LLLQLTNLSATILYEILLG } \\
\text { KATLYAVLVSALVLMA } \\
\text { MVKRKDSRG- }\end{array}$ \\
\hline LM1_V $V_{\delta} C_{\delta} L_{1} i_{\alpha} m_{\alpha}$ & $\begin{array}{l}\text { ATGGAGCGGATCAGCAGCCTGATCCACCTGAGCCT } \\
\text { GTTCTGGGCCGGAGTGATGAGCGCCATCGAGCTGG } \\
\text { TGCCCGAGCACCAGACCGTGCCCGTGAGCATCGGC } \\
\text { GTGCCCGCCACCCTGCGGTGCAGCATGAAGGGCGA } \\
\text { GGCCATCGGCAACTACTACATCAACTGGTACAGAA } \\
\text { AGACCCAGGGCAACACCATGACCTTCATCTACCGG } \\
\text { GAGAAGGACATCTACGGCCCTGGCTTCAAGGACAA } \\
\text { CTTCCAGGGCGACATCGACATCGCCAAGAACCTGG } \\
\text { CCGTGCTGAAGATCCTGGCCCCCAGCGAGAGGGAC } \\
\text { GAGGGCAGCTACTACTGCGCCTGCGACACCCTGGC }\end{array}$ & $\begin{array}{l}\text { MERISSLIHLSLFWAGV } \\
\text { MSAIELVPEHQTVPVSI } \\
\text { GVPATLRCSMKGEAIG } \\
\text { NYYINWYRKTQGNTM } \\
\text { TFIYREKDIYGPGFKDN } \\
\text { FQGDIDIAKNLAVLKIL } \\
\text { APSERDEGSYYCACDT } \\
\text { LATDKLIFGKGTRVTVE } \\
\text { PRSQPHTKPSVFVMK } \\
\text { NGTNVACLVKEFYPKD }\end{array}$ \\
\hline
\end{tabular}




\begin{tabular}{|c|c|c|}
\hline & $\begin{array}{l}\text { CACCGACAAGCTGATCTTCGGCAAGGGCACCCGGG } \\
\text { TGACCGTGGAGCCCAGAAGCCAGCCCCACACCAAG } \\
\text { CCCAGCGTGTTCGTGATGAAGAACGGCACCAACGT } \\
\text { GGCCTGCCTGGTGAAAGAGTTCTACCCCAAGGACA } \\
\text { TCCGGATCAACCTGGTGTCCAGCAAGAAGATCACC } \\
\text { GAGTTCGACCCCGCCATCGTGATCAGCCCAGCGG } \\
\text { CAAGTACAACGCCGTGAAGCTGGGCAAGTACGAGG } \\
\text { ACAGCAACAGCGTGACCTGCAGCGTGCAGCACGAC } \\
\text { AACAAGACCGTGCACAGCACCGACTTCGAGGTGAA } \\
\text { AACCGACTCCACCGACCACGTGAAGCCCAAAGAGA } \\
\text { CCGAGAACACCAAGCAGCCCAGCAAGAGCTGCGA } \\
\text { CGTGAAACTGGTGGAGAAGAGCTTCGAGACCGACA } \\
\text { CCAACCTGAACTTCCAGAACCTGAGCGTGATCGGCT } \\
\text { TCAGAATCCTGCTGCTGAAGGTGGCCGGCTTCAACC } \\
\text { TGCTGATGACCCTGCGGCTGTGGAGCAGCTGAG }\end{array}$ & $\begin{array}{l}\text { IRINLVSSKKITEFDPAIV } \\
\text { ISPSGKYNAVKLGKYED } \\
\text { SNSVTCSVQHDNKTV } \\
\text { HSTDFEVKTDSTDHVK } \\
\text { PKETENTKQPSKSCDV } \\
\text { KLVEKSFETDTNLNFQ } \\
\text { NLSVIGFRILLLKVAGF } \\
\text { NLLMTLRLWSS- }\end{array}$ \\
\hline LM1_V $V_{\delta} C_{\alpha} L_{i} \operatorname{Tm}_{\alpha}$ & $\begin{array}{l}\text { ATGGAGCGGATCAGCAGCCTGATCCACCTGAGCCT } \\
\text { GTTCTGGGCCGGAGTGATGAGCGCCATCGAGCTGG } \\
\text { TGCCCGAGCACCAGACCGTGCCCGTGAGCATCGGC } \\
\text { GTGCCCGCCACCCTGCGGTGCAGCATGAAGGGCGA } \\
\text { GGCCATCGGCAACTACTACATCAACTGGTACAGAA } \\
\text { AGACCCAGGGCAACACCATGACCTTCATCTACCGG } \\
\text { GAGAAGGACATCTACGGCCCTGGCTTCAAGGACAA } \\
\text { CTTCCAGGGCGACATCGACATCGCCAAGAACCTGG } \\
\text { CCGTGCTGAAGATCCTGGCCCCCAGCGAGAGGGAC } \\
\text { GAGGGCAGCTACTACTGCGCCTGCGACACCCTGGC } \\
\text { CACCGACAAGCTGATCTTCGGCAAGGGCACCCGGG } \\
\text { TGACCGTGGAGCCCAACATCCAGAACCCCGACCCC } \\
\text { GCGGTGTACCAGCTGCGGGACAGCAAGAGCAGCG } \\
\text { ACAAGAGCGTGTGCCTGTTCACCGACTTCGACAGC } \\
\text { CAGACCAACGTGAGCCAGAGCAAGGACTCCGACGT } \\
\text { GTACATCACCGACAAGTGCGTGCTGGACATGCGGA } \\
\text { GCATGGACTTCAAGAGCAACTCCGCCGTGGCCTGG } \\
\text { TCCAACAAGAGCGACTTCGCCTGCGCCAACGCCTTC } \\
\text { AACAACAGCATCATCCCCGAGGACACCTTTTCCCC } \\
\text { AGCCCCGAGAGCAGCTGCGACGTGAAACTGGTGGA } \\
\text { GAAGAGCTTCGAGACCGACACCAACCTGAACTTCC } \\
\text { AGAACCTGAGCGTGATCGGCTTCAGAATCCTGCTGC } \\
\text { TGAAGGTGGCCGGCTTCAACCTGCTGATGACCCTGC } \\
\text { GGCTGTGGAGCAGCTGAG }\end{array}$ & $\begin{array}{l}\text { MERISSLIHLSLFWAGV } \\
\text { MSAIELVPEHQTVPVSI } \\
\text { GVPATLRCSMKGEAIG } \\
\text { NYYINWYRKTQGNTM } \\
\text { TFIYREKDIYGPGFKDN } \\
\text { FQGDIDIAKNLAVLKIL } \\
\text { APSERDEGSYYCACDT } \\
\text { LATDKLIFGKGTRVTVE } \\
\text { PNIQNPDPAVYQLRDS } \\
\text { KSSDKSVCLFTDFDSQ } \\
\text { TNVSQSKDSDVYITDK } \\
\text { CVLDMRSMDFKSNSA } \\
\text { VAWSNKSDFACANAF } \\
\text { NNSIIIPEDTFFPSPESSC } \\
\text { DVKLVEKSFETDTNLNF } \\
\text { QNLSVIGFRILLLKVAG } \\
\text { FNLLMTLRLWSS- }\end{array}$ \\
\hline LM1_V $V_{\delta} C_{\delta} \mathrm{Li}_{\delta} \mathrm{Tm}_{\alpha}$ & $\begin{array}{l}\text { ATGGAGCGGATCAGCAGCCTGATCCACCTGAGCCT } \\
\text { GTTCTGGGCCGGAGTGATGAGCGCCATCGAGCTGG } \\
\text { TGCCCGAGCACCAGACCGTGCCCGTGAGCATCGGC } \\
\text { GTGCCCGCCACCCTGCGGTGCAGCATGAAGGGCGA } \\
\text { GGCCATCGGCAACTACTACATCAACTGGTACAGAA } \\
\text { AGACCCAGGGCAACACCATGACCTTCATCTACCGG } \\
\text { GAGAAGGACATCTACGGCCCTGGCTTCAAGGACAA } \\
\text { CTTCCAGGGCGACATCGACATCGCCAAGAACCTGG } \\
\text { CCGTGCTGAAGATCCTGGCCCCCAGCGAGAGGGAC } \\
\text { GAGGGCAGCTACTACTGCGCCTGCGACACCCTGGC } \\
\text { CACCGACAAGCTGATCTTCGGCAAGGGCACCCGGG } \\
\text { TGACCGTGGAGCCCAGAAGCCAGCCCCACACCAAG } \\
\text { CCCAGCGTGTTCGTGATGAAGAACGGCACCAACGT } \\
\text { GGCCTGCCTGGTGAAAGAGTTCTACCCCAAGGACA }\end{array}$ & $\begin{array}{l}\text { MERISSLIHLSLFWAGV } \\
\text { MSAIELVPEHQTVPVSI } \\
\text { GVPATLRCSMKGEAIG } \\
\text { NYYINWYRKTQGNTM } \\
\text { TFIYREKDIYGPGFKDN } \\
\text { FQGDIDIAKNLAVLKIL } \\
\text { APSERDEGSYYCACDT } \\
\text { LATDKLIFGKGTRVTVE } \\
\text { PRSQPHTKPSVFVMK } \\
\text { NGTNVACLVKEFYPKD } \\
\text { IRINLVSSKKITEFDPAIV } \\
\text { ISPSGKYNAVKLGKYED } \\
\text { SNSVTCSVQHDNKTV } \\
\text { HSTDFEVKTDSTDHVK }\end{array}$ \\
\hline
\end{tabular}




\begin{tabular}{|c|c|c|}
\hline & $\begin{array}{l}\text { TCCGGATCAACCTGGTGTCCAGCAAGAAGATCACC } \\
\text { GAGTTCGACCCCGCCATCGTGATCAGCCCCAGCGG } \\
\text { CAAGTACAACGCCGTGAAGCTGGGCAAGTACGAGG } \\
\text { ACAGCAACAGCGTGACCTGCAGCGTGCAGCACGAC } \\
\text { AACAAGACCGTGCACAGCACCGACTTCGAGGTGAA } \\
\text { AACCGACTCCACCGACCACGTGAAGCCCAAAGAGA } \\
\text { CCGAGAACACCAAGCAGCCCAGCAAGAGCTGCCAC } \\
\text { AAGCCCAAGGCCATCGTGCACACCGAGAAGCTGAA } \\
\text { CTTCCAGAACCTGAGCGTGATCGGCTTCAGAATCCT } \\
\text { GCTGCTGAAGGTGGCCGGCTTCAACCTGCTGATGA } \\
\text { CCCTGCGGCTGTGGAGCAGCTGAG }\end{array}$ & $\begin{array}{l}\text { PKETENTKQPSKSCHK } \\
\text { PKAIVHTEKLNFQNLSV } \\
\text { IGFRILLLKVAGFNLLM } \\
\text { TLRLWSS- }\end{array}$ \\
\hline $\mathbf{G} 115_{\gamma_{-}} \mathbf{V}_{\gamma_{-}} C_{\beta_{-}} L_{\beta_{-}} \operatorname{Tm}_{\beta}$ & $\begin{array}{l}\text { ATGGTGTCCCTGCTGCACGCCAGCACCCTGGCCGT } \\
\text { GCTGGGCGCCTTGTGGTGTATGGCGCCGGACACC } \\
\text { TGGAACAGCCCCAGATCAGCAGCACCAAGACCCTG } \\
\text { AGCAAGACCGCCAGGCTGGAATGCGTGGTGTCCGG } \\
\text { CATCACCATCAGCGCCACCTCCGTGTACTGGTACAG } \\
\text { AGAGAGACCCGGCGAGGTCATCCAGTTCCTGGTGT } \\
\text { CCATCAGCTACGACGGCACCGTGCGGAAAGAGAGC } \\
\text { GGCATCCCCAGCGGCAAGTTCGAGGTGGACAGAAT } \\
\text { CCCCGAGACCAGCACCTCCACCCTGACCATCCACA } \\
\text { ACGTGGAGAAGCAGGACATCGCCACCTACTACTGC } \\
\text { GCCCTGTGGGAGGCCCAGCAGGAACTGGGCAAGA } \\
\text { AAATCAAGGTGTTCGGCCCTGGCACCAAGCTGATC } \\
\text { ATCACCGACAAGCAGCTGGACGCCGACGTGAGCCC } \\
\text { CAAGCCTACCATCTTCCTGCCCAGCATCGCCGAGAC } \\
\text { CAAGCTGCAGAAGGCCGGCACCTACCTGTGCCTGC } \\
\text { TGGAAAAGTTCTTCCCCGACGTGATCAAGATCCACT } \\
\text { GGGAGGAAAAGAAGAGCAACACCATCCTGGGCAG } \\
\text { CCAGGAAGGCAATACCATGAAAACCAACGACACCT } \\
\text { ACATGAAGTTCAGCTGGCTGACCGTGCCCGAGAAG } \\
\text { AGCCTGGACAAAGAGCACAGATGCATCGTCCGGCA } \\
\text { CGAGAACAACAAGAACGGCGTGGACCAGGAAATC } \\
\text { ATCTTCCCCCCCATCAAGACCGATGTGATCACAATG } \\
\text { GACCCCAAGGACAACTGCAGCAAGGACGCCAACG } \\
\text { ATACCCTGCTGCTGCAGCTGACCAACCTGTCCGCCA } \\
\text { CCATCCTGTACGAGATCCTGCTGGGCAAGGCCACA } \\
\text { CTGTACGCCGTGCTGGTGTCCGCCCTGGTGCTGATG } \\
\text { GCTATGGTGAAGCGGAAGGACAGCCGGGGTGAG }\end{array}$ & $\begin{array}{l}\text { MVSLLHASTLAVLGAL } \\
\text { CVYGAGHLEQPQISST } \\
\text { KTLSKTARLECVVSGITI } \\
\text { SATSVYWYRERPGEVI } \\
\text { QFLVSISYDGTVRKESG } \\
\text { IPSGKFEVDRIPETSTST } \\
\text { LTIHNVEKQDIATYYCA } \\
\text { LWEAQQELGKKIKVFG } \\
\text { PGTKLIITDKQLDADVS } \\
\text { PKPTIFLPSIAETKLQKA } \\
\text { GTYLCLLEKFFPDVIKIH } \\
\text { WEEKKSNTILGSQEGN } \\
\text { TMKTNDTYMKFSWLT } \\
\text { VPEKSLDKEHRCIVRHE } \\
\text { NNKNGVDDQEIIFPPIKT } \\
\text { DVITMDPKDNCSKDA } \\
\text { NDTLLLQLTNLSATILY } \\
\text { EILLGKATLYAVLVSALV } \\
\text { LMAMVKRKDSRG- }\end{array}$ \\
\hline $\mathbf{G 1 1 5}_{\gamma_{-}} \mathrm{V}_{\mathrm{\gamma}} \mathrm{C}_{\gamma_{-}} \mathrm{Li}_{\beta} \mathrm{Tm}_{\beta}$ & $\begin{array}{l}\text { ATGGTGTCCCTGCTGCACGCCAGCACCCTGGCCGT } \\
\text { GCTGGGCGCCCTGTGCGTGTATGGCGCCGGACACC } \\
\text { TGGAACAGCCCCAGATCAGCAGCACCAAGACCCTG } \\
\text { AGCAAGACCGCCAGGCTGGAATGCGTGGTGTCCGG } \\
\text { CATCACCATCAGCGCCACCTCCGTGTACTGGTACAG } \\
\text { AGAGAGACCCGGCGAGGTCATCCAGTTCCTGGTGT } \\
\text { CCATCAGCTACGACGGCACCGTGCGGAAAGAGAGC } \\
\text { GGCATCCCCAGCGGCAAGTTCGAGGTGGACAGAAT } \\
\text { CCCCGAGACCAGCACCTCCACCCTGACCATCCACA } \\
\text { ACGTGGAGAAGCAGGACATCGCCACCTACTACTGC } \\
\text { GCCCTGTGGGAGGCCAGCAGGAACTGGGCAAGA } \\
\text { AAATCAAGGTGTTCGGCCCTGGCACCAAGCTGATC } \\
\text { ATCACCGACAAGCAGCTGGACGCCGACGTGAGCCC } \\
\text { CAAGCCTACCATCTTCCTGCCCAGCATCGCCGAGAC } \\
\text { CAAGCTGCAGAAGGCCGGCACCTACCTGTGCCTGC }\end{array}$ & $\begin{array}{l}\text { MVSLLHASTLAVLGAL } \\
\text { CVYGAGHLEQPQISST } \\
\text { KTLSKTARLECVVSGITI } \\
\text { SATSVYWYRERPGEVI } \\
\text { QFLVSISYDGTVRKESG } \\
\text { IPSGKFEVDRIPETSTST } \\
\text { LTIHNVEKQDIATYYCA } \\
\text { LWEAQQELGKKIKVFG } \\
\text { PGTKLIITDKQLDADVS } \\
\text { PKPTIFLPSIAETKLQKA } \\
\text { GTYLCLLEKFFPDVIKIH } \\
\text { WEEKKSNTILGSQEGN } \\
\text { TMKTNDTYMKFSWLT } \\
\text { VPEKSLDKEHRCIVRHE } \\
\text { NNKNGVVDQEIIFPPIKT }\end{array}$ \\
\hline
\end{tabular}




\begin{tabular}{|c|c|c|}
\hline & $\begin{array}{l}\text { TGGAAAAGTTCTTCCCCGACGTGATCAAGATCCACT } \\
\text { GGGAGGAAAAGAAGAGCAACACCATCCTGGGCAG } \\
\text { CCAGGAAGGCAATACCATGAAAACCAACGACACCT } \\
\text { ACATGAAGTTCAGCTGGCTGACCGTGCCCGAGAAG } \\
\text { AGCCTGGACAAAGAGCACAGATGCATCGTCCGGCA } \\
\text { CGAGAACAACAAGAACGGCGTGGACCAGGAAATC } \\
\text { ATCTTCCCCCCCATCAAGACCGATGTGATCACAATG } \\
\text { GACCCCAAGGACAACTGCGGCTTCACCAGCGAGAG } \\
\text { CTACCAGCAGGGCGTGCTGTCCGCCACCATCCTGTA } \\
\text { CGAGATCCTGCTGGGCAAGGCCACACTGTACGCCG } \\
\text { TGCTGGTGTCCGCCCTGGTGCTGATGGCTATGGTGA } \\
\text { AGCGGAAGGACAGCCGGGGCTGA }\end{array}$ & $\begin{array}{l}\text { DVITMDPKDNCGFTSE } \\
\text { SYQQGVLSATILYEILLG } \\
\text { KATLYAVLVSALVLMA } \\
\text { MVKRKDSRG- }\end{array}$ \\
\hline $\mathbf{G} 115_{\gamma_{-}} \mathrm{V}_{\mathrm{\gamma}} \mathrm{C}_{\gamma} \mathrm{Li}_{\gamma_{-}} \mathrm{Tm}_{\beta}$ & $\begin{array}{l}\text { ATGGTGTCCCTGCTGCACGCCAGCACCCTGGCCGT } \\
\text { GCTGGGCGCCCTGTGCGTGTATGGCGCCGGACACC } \\
\text { TGGAACAGCCCCAGATCAGCAGCACCAAGACCCTG } \\
\text { AGCAAGACCGCCAGGCTGGAATGCGTGGTGTCCGG } \\
\text { CATCACCATCAGCGCCACCTCCGTGTACTGGTACAG } \\
\text { AGAGAGACCCGGCGAGGTCATCCAGTTCCTGGTGT } \\
\text { CCATCAGCTACGACGGCACCGTGCGGAAAGAGAGC } \\
\text { GGCATCCCCAGCGGCAAGTTCGAGGTGGACAGAAT } \\
\text { CCCCGAGACCAGCACCTCCACCCTGACCATCCACA } \\
\text { ACGTGGAGAAGCAGGACATCGCCACCTACTACTGC } \\
\text { GCCCTGTGGGAGGCCCAGCAGGAACTGGGCAAGA } \\
\text { AAATCAAGGTGTTCGGCCCTGGCACCAAGCTGATC } \\
\text { ATCACCGACAAGCAGCTGGACGCCGACGTGAGCCC } \\
\text { CAAGCCTACCATCTTCCTGCCCAGCATCGCCGAGAC } \\
\text { CAAGCTGCAGAAGGCCGGCACCTACCTGTGCCTGC } \\
\text { TGGAAAAGTTCTTCCCCGACGTGATCAAGATCCACT } \\
\text { GGGAGGAAAAGAAGAGCAACACCATCCTGGGCAG } \\
\text { CCAGGAAGGCAATACCATGAAAACCAACGACACCT } \\
\text { ACATGAAGTTCAGCTGGCTGACCGTGCCCGAGAAG } \\
\text { AGCCTGGACAAAGAGCACAGATGCATCGTCCGGCA } \\
\text { CGAGAACAACAAGAACGGCGTGGACCAGGAAATC } \\
\text { ATCTTCCCCCCCATCAAGACCGATGTGATCACAATG } \\
\text { GACCCCAAGGACAACTGCAGCAAGGACGCCAACG } \\
\text { ATACCCTGCTGCTGCAGCTGACCAACCTGTCCGCCA } \\
\text { CCATCCTGTACGAGATCCTGCTGGGCAAGGCCACA } \\
\text { CTGTACGCCGTGCTGGTGTCCGCCCTGGTGCTGATG } \\
\text { GCTATGGTGAAGCGGAAGGACAGCCGGGGTGA }\end{array}$ & $\begin{array}{l}\text { MVSLLHASTLAVLGAL } \\
\text { CVYGAGHLEQPQISST } \\
\text { KTLSKTARLECVVSGITI } \\
\text { SATSVYWYRERPGEVI } \\
\text { QFLVSISYDGTVRKESG } \\
\text { IPSGKFEVDRIPETSTST } \\
\text { LTIHNVEKQDIATYYCA } \\
\text { LWEAQQELGKKIKVFG } \\
\text { PGTKLIITDKQLDADVS } \\
\text { PKPTIFLPSIAETKLQKA } \\
\text { GTYLCLLEKFFPDVIKIH } \\
\text { WEEKKSNTILGSQEGN } \\
\text { TMKTNDTYMKFSWLT } \\
\text { VPEKSLDKEHRCIVRHE } \\
\text { NNKNNGVDQEIIFPPIKT } \\
\text { DVITMDPKDNCSKDA } \\
\text { NDTLLLQLTNLSATILY } \\
\text { EILLGKATLYAVLVSALV } \\
\text { LMAMVKRKDSRG- }\end{array}$ \\
\hline Cl5_ $V_{\gamma \beta} C_{\beta} L_{\beta} T m_{\beta}$ & $\begin{array}{l}\text { ATGGTGAGCCTGCTGCACGCCAGCACCCTGGCCGT } \\
\text { GCTGGGCGCCCTGTGCGTGTACGGGGCCGGGCACC } \\
\text { TGGAGCAGAACCCCCGGCATAAGATCACCAAGCTG } \\
\text { AGCAAGACCGCCCGGCTGGAGTGCGTGGTGTCCGG } \\
\text { CATCACAATTAGCGCCACCAGCGTGTACTGGTACCG } \\
\text { GGAGCGGCCTGGCGAGGTCATCCAGTTCCTGGTCA } \\
\text { GCATCTCCTACGATGGGACCGTGAGGAAGGAGAGC } \\
\text { GGCATTCCCAGCGGCAAGTTCGAGGTGGATAGGAT } \\
\text { TCCCGAGACAAGCACAAGCACCCTGACAATCCACA } \\
\text { ACGTGGAGAAGCAGGACATCGCCACATACTACTGC } \\
\text { GCCCTGTGGGAGATCCAGGAGCTGGGGAAGAAAAT } \\
\text { TAAGGTGTTTGGACCCGGAACAAGACTCACTGTGCT } \\
\text { TGAAGACCTGAAGAACGTCTTCCCCCCGAGGTGG } \\
\text { CTGTCTTTGAACCTTCCGAGGCCGAATCAGTCACA }\end{array}$ & $\begin{array}{l}\text { MVSLLHASTLAVLGAL } \\
\text { CVYGAGHLEQNPRHKI } \\
\text { TKLSKTARLECVVSGITI } \\
\text { SATSVYWYRERPGEVI } \\
\text { QFLVSISYDGTVRKESG } \\
\text { IPSGKFEVDRIPETSTST } \\
\text { LTIHNVEKQDIATYYCA } \\
\text { LWEIQELGKKIKVFGPG } \\
\text { TRLTVLEDLKNVFPPEV } \\
\text { AVFEPSEAEISHTQKAT } \\
\text { LVCLATGFYPDHVELS } \\
\text { WWVNGKEVHSGVCT } \\
\text { DPQPLKEQPALNDSRY } \\
\text { CLSSRLRVSATFWHNP }\end{array}$ \\
\hline
\end{tabular}




\begin{tabular}{|c|c|c|}
\hline & $\begin{array}{l}\text { CCCAGAAGGCCACTCTGGTCTGTCTCGCCACCGGCT } \\
\text { TCTACCCCGATCACGTGGAGTTGAGCTGGTGGGTCA } \\
\text { ACGGGAAAGAGGTCCACTCAGGGGTCTGTACCGAC } \\
\text { CCCCAGCCATTGAAAGAGCAGCCAGCCCTCAACGA } \\
\text { CAGCCGGTACTGCCTGAGCTCCAGACTCCGGGTGA } \\
\text { GCGCCACATTCTGGCATAACCCTAGGAATCACTTCA } \\
\text { GGTGCCAGGTGCAG } \\
\text { TTTCATGGCCTGTCAGAGAACGATAAGTGGCCTGAA } \\
\text { GGCTCCGCCAAGCCTGTGACTCAGAACATCAGCGC } \\
\text { AGAGGCCTGGGGGCGGGCCGACTGCGGGTTTACCT } \\
\text { CTGAGTCCTACCAGCAGGGAGTGCTGAGCGCGACC } \\
\text { ATCCTGTACGAGATCCTGCTGGGCAAGGCCACACT } \\
\text { GTACGCCGTGCTGGTGAGCGCCCTGGTGCTGATGG } \\
\text { CTATGGTGAAGAGGAAGGACTCCAGGGGCTGA }\end{array}$ & $\begin{array}{l}\text { RNHFRCQVQFHGLSE } \\
\text { NDKWPEGSAKPVTQN } \\
\text { ISAEAWGRADCGFTSE } \\
\text { SYQQGVLSATILYEILLG } \\
\text { KATLYAVLVSALVLMA } \\
\text { MVKRKDSRG- }\end{array}$ \\
\hline Cl5_V $V_{\gamma-} C_{\gamma \beta} L_{\beta} T^{T} m_{\beta}$ & $\begin{array}{l}\text { ATGGTGAGCCTGCTGCACGCCAGCACACTGGCCGT } \\
\text { GTTGGGCGCTCTGTGCGTGTACGGAGCCGGCCATTT } \\
\text { GGAGCAGCCACAGATTAGCAGCACCAAGACCCTGT } \\
\text { CCAAGACCGCCAGGCTGGAGTGCGTGGTGTCCGGG } \\
\text { ATTACCATTAGCGCCACATCCGTGTACTGGTACCGG } \\
\text { GAGCGGCCCGGAGAGGTCATCCAGTTCCTGGTGAG } \\
\text { CATCAGCTACGATGGCACAGTGAGGAAGGAGTCAG } \\
\text { GCATTCCCTCCGGCAAGTTCGAGGTGATCGGATTC } \\
\text { CCGAGACCTCCACATCCACACTGACAATTCACAACG } \\
\text { TGGAGAAGCAGGATATTGCCACATACTACTGCGCC } \\
\text { CTGTGGGAGATCCAGGAGCTGGGCAAGAAGATCAA } \\
\text { GGTGTTCGGCCCAGGGACAAAGCTGATCATCACAG } \\
\text { AGGACCTGAACAAGGTGTTTCCCCCCAGGTGGCC } \\
\text { GTGTTTGAGCCCTCCGAGGCCGAGATCTCCCACACC } \\
\text { CAGAAGGCCACCCTGGTGTGCCTGGCCACCGGGTT } \\
\text { CTTCCCTGACCACGTGGAGCTGAGCTGGTGGGTGA } \\
\text { ACGGCAAGGAGGTCCACAGCGGCGTGTGCACCGA } \\
\text { CCCCCAGATGCTGAAGGAGCAGCCCGCCCTCAACG } \\
\text { ATTCCCGGTACTGCCTGTTIAGCTGGCTGAGGGTGA } \\
\text { GCGCCACATTTTGGCAGAACCCTAGGAACCACTTCA } \\
\text { GGTGCCAGGTGCAGTTCCACGGCTTGAGCGAGAAC } \\
\text { GATAAGTGGCCTGAAGGCAGCGCCAAACCCGTGAC } \\
\text { CCAGAACATCAGCGCTGAGGCCTGGGGGCGGCT } \\
\text { GATTGCGGATTCACTAGTGAGTCCTACCAGCAGGG } \\
\text { GGTGCTGAGCGCCACAATCCTGTACGAAATCCTGCT } \\
\text { GGGTAAGGCCACCCTGTACGCCGTGCTGGTGAGCG } \\
\text { CCCTGGTGCTGATGGCTATGGTGAAGAGGAAGGAC } \\
\text { AGCCGGGTGA }\end{array}$ & $\begin{array}{l}\text { MVSLLHASTLAVLGAL } \\
\text { CVYGAGHLEQPQISST } \\
\text { KTLSKTARLECVVSGITI } \\
\text { SATSVYWYRERPGEVI } \\
\text { QFLVSISYDGTVRKESG } \\
\text { IPSGKFEVDRIPETSTST } \\
\text { LTIINVEKQDIATYYCA } \\
\text { LWEIQELGKKIKVFGPG } \\
\text { TKLIITEDLNKVFPPEVA } \\
\text { VFEPSEAEISHTQKATL } \\
\text { VCLATGFFPDHVELSW } \\
\text { WVNGKEVHSGVCTDP } \\
\text { QMLKEQPALNDSRYC } \\
\text { LFSWLRVSATFWQNP } \\
\text { RNHFRCQVQFHGLSE } \\
\text { NDKWPEGSAKPVTQN } \\
\text { ISAEAWGRADCGFTSE } \\
\text { SYQQGVLSATILYEILLG } \\
\text { KATLYAVLVSALVLMA } \\
\text { MVKRKDSRG- }\end{array}$ \\
\hline Cl5_ $V_{\alpha \delta} C_{\alpha \delta} L_{i} \operatorname{Tm}_{\alpha}$ & $\begin{array}{l}\text { ATGGAAAGGATTAGCTCCCTGATCCACCTGAGCCTG } \\
\text { TTCTGGGCCGGCGTGATGAGCGCCATTGAGCTGGT } \\
\text { CCCCGAGCACCAGACAGTGCCTGTGAGCATCGGCG } \\
\text { TGCCTGCCACCCTGAGGTGCAGCATGAAGGGAGAG } \\
\text { GCCATCGGAAACTACTACATTAACTGGTACAGAAA } \\
\text { GACACAGGGGAACACTATGACATTCATCTACAGGG } \\
\text { AGAAGGATATCTACGGCCCTGGGTTTAAGGATAACT } \\
\text { TTCAGGGAGATATCGATATCGCTAAGAACTTGGCCG } \\
\text { TGCTGAAGATTCTGGCCCCAAGCGAGAGAGATGAA } \\
\text { GGATCTTACTACTGCGCCTGCGATGCCCTGAAGCGG } \\
\text { ACAGAT }\end{array}$ & $\begin{array}{l}\text { MERISSLIHLSLFWAGV } \\
\text { MSAIELVPEHQTVPVSI } \\
\text { GVPATLRCSMKGEAIG } \\
\text { NYYINWYRKTQGNTM } \\
\text { TFIYREKDIYGPGFKDN } \\
\text { FQGDIDIAKNLAVLKIL } \\
\text { APSERDEGSYYCACDA } \\
\text { LKRTDTDKLIFGKGTRV } \\
\text { TVEPNIQNPDPAVFQ } \\
\text { MRNSKSSDKSVCLFTD } \\
\text { FDSQTNVSQSKDSDVF }\end{array}$ \\
\hline
\end{tabular}




\begin{tabular}{|c|c|c|}
\hline & $\begin{array}{l}\text { ACAGACAAGTTGATCTTTGGCAAGGGGACAAGAGT } \\
\text { GACAGTCGAGCCTAACATTCAGAACCCCGATCCCG } \\
\text { CCGTGTTCCAGATGCGGAACAGCAAGTCCAGCGAT } \\
\text { AAGAGCGTGTGCCTGTTCACAGATTTCGATAGCCAG } \\
\text { ACAAACGTGAGCCAGAGCAAGGACAGCGACGTGTT } \\
\text { CATTACAGATAAGTGCGTGCTGGACATGCGGAGCA } \\
\text { TGGATTTCAAGAGCAACAGCGCCGTGGCCTGGAGC } \\
\text { AACAAGAGCGATTTCGCCTGCGCCAACGCCTTCAA } \\
\text { CAACAGCATCATCCCCGAGGATACCTTCTTCCCCAG } \\
\text { CCCAGAGAGCAGCTGCGACGTGAAGCTGGTGGAG } \\
\text { AAGAGCTTCGAGACAGATACAAACCTGAACTTCCA } \\
\text { GAACCTGAGCGTGATCGGGTTCAGAATCCTGCTGCT } \\
\text { GAAGGTGGCCGGCTTCAACCTGCTGATGACACTGA } \\
\text { GGCTGTGGAGCAGCTGA }\end{array}$ & $\begin{array}{l}\text { ITDKCVLDMRSMDFKS } \\
\text { NSAVAWSNKSDFACA } \\
\text { NAFNNSIIPEDTFFPSP } \\
\text { ESSCDVKLVEKSFETDT } \\
\text { NLNFQNLSVIGFRILLL } \\
\text { KVAGFNLLMTLRLWSS } \\
-\end{array}$ \\
\hline Cl5_ $V_{\gamma \beta} C_{\gamma \beta} L_{i} \operatorname{Tm}_{\beta}$ & $\begin{array}{l}\text { ATGGTGAGCCTGCTGCACGCCAGTACCCTGGCCGT } \\
\text { GCTGGGAGCATTGTGCGTGTACGGGGCCGGGCATT } \\
\text { TGGAACAGAACCCTAGACACAAGATTACTAAATTGT } \\
\text { CTAAAACAGCTAGACTTGAATGTGTCGTGAGCGGA } \\
\text { ATTACGATTAGTGCCACAAGCGTCTACTGGTACAGA } \\
\text { GAGAGACCTGGCGAAGTGATCCAGTTCCTGGTGAG } \\
\text { CATTAGCTACGATGGGACAGTCCGGAAGGAGAGCG } \\
\text { GCATCCCCTCCGGGAAGTTCGAGGTGGATAGAATT } \\
\text { CCTGAGACAAGCACAAGCACCCTGACCATCCACAA } \\
\text { CGTGGAGAAGCAGGACATCGCCACCTACTACTGCG } \\
\text { CCCTCTGGGAGATCCAGGAGCTGGGGAAGAAGATT } \\
\text { AAGGTGTTTGGCCCCGCACTAGGCTGACCGTGCT } \\
\text { GGAGGACCTGAACAAGGTGTTCCCCCCCGAGGTCG } \\
\text { CCGTGTTCGAGCCTAGCGAGGCCGAGATTAGCCAC } \\
\text { ACCCAGAAGGCCACCCTGGTGTGCCTGGCCACCGG } \\
\text { GTTCTTTCCCGACCACGTGGAGCTGTCCTGGTGGGT } \\
\text { GAACGGCAAGGAGGTCCACAGCGGCGTGTGCACA } \\
\text { GATCCCCAGATGCTCAAGGAGCAGCCCGCCCTGAA } \\
\text { CGATAGCAGGTACTGCCTGTTCAGCTGGCTGCGGG } \\
\text { TGAGCGCCACATTCTGGCAGAACCCCGGAACCAC } \\
\text { TTCCGGTGCCAGGTGCAGTTCCACGGGCTGAGCGA } \\
\text { GAACGATAAGTGGCCCGAGGGCAGCGCCAAGCCC } \\
\text { GTGACACAGAACATCTCCGCCGAGGCCTGGGGGCG } \\
\text { GGCCGACTGCGGGTTTACATCCGAGAGCTACCAGC } \\
\text { AGGGCGTGCTGTCCGCCACAATCCTGTACGAGATC } \\
\text { CTGCTGGGGAAGGCCACACTGTACGCCGTCCTGGT } \\
\text { GAGCGCCCTGGTGCTGATGGCTATGGTGAAGAGGA } \\
\text { AGGACAGCAGGGGGTGA }\end{array}$ & $\begin{array}{l}\text { MVSLLHASTLAVLGAL } \\
\text { CVYGAGHLEQNPRHKI } \\
\text { TKLSKTARLECVVSGITI } \\
\text { SATSVYWYRERPGEVI } \\
\text { QFLVSISYDGTVRKESG } \\
\text { IPSGKFEVDRIPETSTST } \\
\text { LTIHNVEKQDIATYYCA } \\
\text { LWEIQELGKKIKVFGPG } \\
\text { TRLTVLEDLNKVFPPEV } \\
\text { AVFEPSEAEISHTQKAT } \\
\text { LVCLATGFFPDHVELS } \\
\text { WWVNGKEVHSGVCT } \\
\text { DPQMLKEQPALNDSR } \\
\text { YCLFSWLRVSATFWQ } \\
\text { NPRNHFRCQVQFHGL } \\
\text { SENDKWPEGSAKPVT } \\
\text { QNISAEAWGRADCGF } \\
\text { TSESYQQGVLSATILYEI } \\
\text { LLGKATLYAVLVSALVL } \\
\text { MAMVKRKDSRG- }\end{array}$ \\
\hline
\end{tabular}




\begin{tabular}{|c|c|c|c|}
\hline & Primer name & $\begin{array}{c}\text { Sequence } \\
\left(5^{\prime}-3^{\prime}\right)\end{array}$ & Remarks \\
\hline \multirow{5}{*}{ 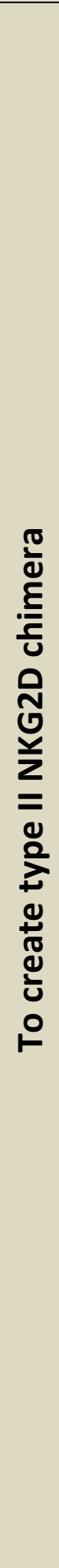 } & CD28cyto_FW1 & $\begin{array}{l}\text { ATT CCA TGG GTA } \\
\text { GAA GCA AG }\end{array}$ & $\begin{array}{l}\text { Used to make NKG2D- } \\
\text { CD28 type II construct. }\end{array}$ \\
\hline & ICOScyto_FW1 & $\begin{array}{l}\text { TTT CCA TGG GTT GCT } \\
\text { GG }\end{array}$ & $\begin{array}{l}\text { Used to make NKG2D- } \\
\text { ICOS type II construct. }\end{array}$ \\
\hline & NKG2D_OIEx_RV1 & $\begin{array}{l}\text { GCAGCAGAAAAAGA } \\
\text { AGGG }\end{array}$ & $\begin{array}{c}\text { Used together with } \\
\text { primers CD28cyto_FW1 or } \\
\text { ICOScyto_FW1 to make } \\
\text { NKG2D-CD28 type II and } \\
\text { NKG2D-ICOS type II } \\
\text { constructs. } \\
\text { DNA template used: } \\
\text { CD28cyto-NKG2D tm (18 } \\
\text { nt) or ICOScyto-NKG2D tm } \\
\text { (18 nt) }\end{array}$ \\
\hline & NKG2D_BamHI_RV2 & $\begin{array}{c}\text { ATT GGA TCC TCA GAC } \\
\text { GGT C }\end{array}$ & $\begin{array}{l}\text { Used to make NKG2D- } \\
\text { CD28 and NKG2D-ICOS } \\
\text { type II constructs. }\end{array}$ \\
\hline & NKG2D_FW2 & $\begin{array}{c}\text { CCCTTCTTTTTCTGCT } \\
\text { GC }\end{array}$ & $\begin{array}{l}\text { Used together with primer } \\
\text { NKG2D_BamHI_RV2 to } \\
\text { make NKG2D-CD28 type II } \\
\text { and NKG2D-ICOS type II } \\
\text { constructs. } \\
\text { DNA template used: type II } \\
\text { 4-1BBcyto-NKG2D tm + ec }\end{array}$ \\
\hline
\end{tabular}




\begin{tabular}{|c|c|c|c|}
\hline \multirow{5}{*}{ 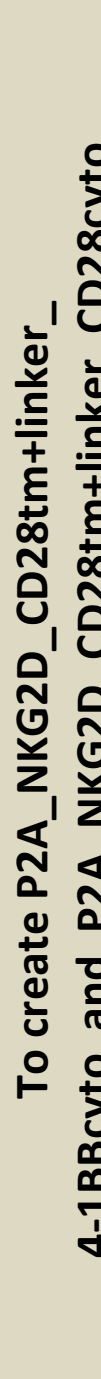 } & P2A_FW2 & $\begin{array}{c}\text { CGC CAA GCT GTT } \\
\text { CTT CCT GC }\end{array}$ & $\begin{array}{c}\text { To amplify: } \\
\text { NKG2D_CD28linker_CD28T } \\
\text { M }\end{array}$ \\
\hline & CD28tm_RV2 & $\begin{array}{l}\text { GAC CCA GAA GAT } \\
\text { GAT GAA GGC CAC }\end{array}$ & $\begin{array}{c}\text { To amplify: } \\
\text { NKG2D_CD28linker_CD28T } \\
\text { M }\end{array}$ \\
\hline & 41BBcyto_FW1 & $\begin{array}{c}\text { TTCATCATCTTCTGG } \\
\text { GTCAAGCG GGG } \\
\text { GAG GAA GAA ACT } \\
\text { C }\end{array}$ & To amplify: 41BB cyto \\
\hline & pmp71_RV & $\begin{array}{l}\text { GGC TCG TGT TAA } \\
\text { GCT TTC ACA }\end{array}$ & $\begin{array}{c}\text { To amplify: 41BB cyto and } \\
\text { ICOS }\end{array}$ \\
\hline & ICOS_FW1 & $\begin{array}{c}\text { TTCATCATCTTCTGG } \\
\text { GTCTGT TGG CTT } \\
\text { ACA AAG AAA AAG } \\
\text { TAC AGC T }\end{array}$ & To amplify: ICOS cyto \\
\hline
\end{tabular}

